UNIVERSIDADE DE SÃO PAULO

ESCOLA DE ARTES, CIÊNCIAS E HUMANIDADES

PROGRAMA DE PÓS-GRADUAÇÃO EM CIÊNCIAS DA ATIVIDADE FÍSICA

MAELY PEDROSA PIMENTEL

Análise do desempenho de tarefa virtual em pessoas com Síndrome de Down 
MAELY PEDROSA PIMENTEL

\section{Análise do desempenho de tarefa virtual em pessoas com Síndrome de Down}

Versão original

Dissertação apresentada à Escola de Artes, Ciências e Humanidades da Universidade de São Paulo para obtenção do título de Mestre em Ciências pelo Programa de Pós-graduação em Ciência da Atividade Física

Área de Concentração:

Desempenho Físico e Motor.

Orientador:

Prof. Dr. Fernando Henrique Magalhães

São Paulo 
Autorizo a reprodução e divulgação total ou parcial deste trabalho, por qualquer meio convencional ou eletrônico, para fins de estudo e pesquisa, desde que citada a fonte.

CATALOGAÇÃO-NA-PUBLICAÇÃO

(Universidade de São Paulo. Escola de Artes, Ciências e Humanidades. Biblioteca) CRB 8 - 4936

Pimentel, Maely Pedrosa

Análise do desempenho de tarefa virtual em pessoas com Síndrome de Down / Maely Pedrosa Pimentel ; orientador, Fernando Henrique Magalhães. - 2020

$62 \mathrm{f}:$ il.

Dissertação (Mestrado em Ciências) - Programa de PósGraduação em Ciências da Atividade Física, Escola de Artes, Ciências e Humanidades, Universidade de São Paulo. Versão original

1. Desempenho motor. 2. Habilidades motoras. 3. Síndrome de down. 4. Realidade virtual - Aplicações terapêuticas. 5. Aprendizagem motora. I. Magalhães, Fernando Henrique, orient. II. Título 
Nome: PIMENTEL, Maely Pedrosa

Título: Análise do desempenho de tarefa virtual em pessoas com Síndrome de Down

Dissertação apresentada à Escola de Artes, Ciências e Humanidades da Universidade de São Paulo para obtenção do título de Mestre em Ciências do Programa de Pós-Graduação em Ciências da Atividade Física.

Área de Concentração:

Desempenho Físico e Motor

Aprovada em: l

\section{Banca Examinadora}

Prof. Dr.

Julgamento:

Prof. Dr.

Julgamento:

Prof. Dr.

Julgamento:
Instituição:

Assinatura:

Instituição:

Assinatura:

Instituição:

Assinatura: 


\section{Agradecimentos}

Nesses anos de mestrado, de muito empenho, não poderia deixar de agradecer o preciso apoio de algumas pessoas, que me acompanharam e foram fundamentais neste período. Então expresso aqui com sinceras palavras minha gratidão a todas elas.

Em primeiro lugar agradeço a Deus, pois sempre esteve comigo, me direcionando e possibilitando vencer desafios e alcançar sonhos.

Agradeço aos meus pais Eliezer e Izalete pelo apoio, por sempre acreditarem e investirem em mim, com fé e dedicação. Agradeço a minha irmã Noemi, que sacrificou seu tempo, sem reservas, para me ajudar nos momentos difíceis, o seu apoio foi fundamental no início deste trabalho. Ao meu marido Gilmar, que foi compreensivo e companheiro, se dedicou de forma inexplicável aos cuidados da família nos momentos que precisei me ausentar. Agradeço também a minha tia Neide que de forma acolhedora me recebeu em sua casa e viabilizou minha estadia em São Paulo. À toda minha família, serei eternamente grata!

À minha amiga e sócia Renata Mota, que se sacrificou durante o período que não estive presente na empresa, sua amizade e parceria são presentes de Deus pra mim.

Aos amigos do grupo da Escola de Artes, Ciências e Humanidades, ah!! Não tenho palavras para expressar meus sentimentos. Esse grupo ocupará para sempre um espaço meu coração! À Íbis Ariana Peña de Moares que sempre se mostrou proativa e nunca mediu esforços para ajudar desde o ato da minha inscrição até a leitura final da tese, serei eternamente grata a você e desejo que Deus te abençoe de forma extraordinária. À Tânia Crocetta que me incentivou a embarcar neste sonho, sempre me atendeu prontamente para a instalação dos jogos, resolveu todos os problemas com o computador durante o a coleta, sua paciência e carinho refletem em mim com muito amor. À Talita Dias da Silva que disponibilizou seu tempo para me ajudar na análise, e compartilhar seu conhecimento tirando as inúmeras dúvidas que eu tenho. Ao Prof. Dr. Carlos Bandeira de Mello Monteiro agradeço por abrir as portas, por acreditar em mim e pela confiança.

Ao meu orientador, Prof. Dr. Fernando Henrique Magalhães, pela oportunidade, incentivo e disponibilidade. 


\section{RESUMO}

PIMENTEL, Maely Pedrosa. Análise do desempenho de tarefa virtual em pessoas com Síndrome de Down. 2020. 62p. Dissertação (Mestrado em Ciências). Escola de Artes, Ciências e Humanidades, Universidade de São Paulo, São Paulo, 2020. Versão original.

A síndrome de Down (SD) é uma condição genética, caracterizada pela trissomia do cromossomo 21 e pode presentar distúrbios que interferem nas aquisições motoras, funcionalidade e independência para realização das atividades de vida diária. A expectativa de vida destas pessoas tem aumentado significativamente na população geral e o desenvolvimento vai depender diretamente dos programas de estímulos oferecidos, tendo como possibilidade a intervenção baseada no conhecimento de aprendizagem. Sendo assim uma das ferramentas que podem ser úteis no suporte ao desenvolvimento global e para a reabilitação é a realidade virtual $(\mathrm{RV})$, logo torna-se importante estudar o processo de aprendizagem motora em indivíduos com SD durante tarefa de RV para justificar seu uso em programas de intervenção. O presente estudo tem como objetivo analisar se as pessoas com SD são capazes de melhorar o desempenho em tarefas de RV utilizamos dois softwares: Check Limits e Timing Coincident e para averigar o tempo de reação foi utilizado o TRT. Para a realização deste trabalho foram avaliadas 122 pessoas, divididas em dois grupos: 61 no grupo SD, com idade entre 8 e 50 anos (22 $\pm 9,32$ anos), 38 do sexo masculino e 23 do sexo feminino e 61 pessoas com desenvolvimento típico (DT), pareados por idade e sexo ao grupo SD. Os resultados apontam que os indivíduos com SD melhoraram o desempenho em tarefa virtual, isso foi evidenciado no software Check Limits, com aumento da quantidade das bolhas alcançadas no decorrer do jogo e no Timing Coincidente com menor erro de temporização com a prática, sendo capazes de manter o desempenho no período de retenção e transferir para uma tarefa com velocidade aumenta, logo, a MANOVA que revelou efeito significativo para grupo [Wilks lambda $=0.641, \mathrm{~F}(3,117)=21,9, \mathrm{p}<0.001$, $\eta_{\mathrm{p}}{ }^{2}=0.36$ ] e Blocos [Wilks 'lambda $=0.590, \mathrm{~F}(3,117)=27.1, \mathrm{p}<0.001, \eta_{\mathrm{p}}{ }^{2}=0.41$ ]. Na mensuração do Tempo de Reação Total (TRT) houve diferença significativa entre Blocos para ambos os grupos SD (bloco 1: 2333 $\pm 1267 \mathrm{~ms}$; bloco 2: 1741 $\pm 1279 \mathrm{~ms}$; $\mathrm{p}<0.001$ ), demonstrando maior capacidade para reagir a um estímulo em menor tempo. Podemos concluir que pessoas com SD melhoraram seu desempenho durante a prática em tarefas virtuais, desta forma, estes jogos podem contribuir para aprendizagem motora destes indivíduos.

Palavras-chave: Síndrome de Down. Habilidades Motoras. Realidade Virtual. 


\begin{abstract}
PIMENTEL, Maely Pedrosa. Analysis of virtual task performance in people with Down syndrome. 2020. 62p. Dissertation (Master of Science). School of Arts, Sciences and Humanities, University of São Paulo, São Paulo, 2020. Original Version.

Down syndrome (DS) is a genetic condition, characterized by the trisomy of chromosome 21 and can present disorders that interfere with motor acquisitions, functionality, and independence to perform activities of daily living. The life expectancy of these people has increased significantly in the general population and development will depend directly on the stimulus programs offered, with the possibility of intervention based on learning knowledge. Thus, one of the tools that can be useful in supporting global development and for rehabilitation is virtual reality (VR), so it becomes important to study the motor learning process in individuals with DS during VR tasks to justify its use in intervention programs. The present study aims to analyze whether people with DS can improve performance in VR tasks. We use two software: Check Limits and Timing Coincident and to verify the reaction time, TRT was used. For this work, 120 people were evaluated, divided into two groups: 60 in the DS group, aged between 8 and 50 years ( $22 \pm 9.32$ years), 37 males and 23 females and 60 people with typical development (TD), matched for age and sex to the DS group. The results show that individuals with DS improved their performance in a virtual task, this was evidenced in the Check Limits software, with an increase in the number of bubbles reached during the game and in the Coincident Timing with less timing error with the practice, being able to maintaining performance in the retention period and transferring to a task with speed increases, therefore, the MANOVA which revealed a significant effect for the group [Wilks lambda $=0.641, \mathrm{~F}(3$, $\left.117)=21.9, \mathrm{p}<0.001, \eta_{\mathrm{p}}{ }^{2}=0.36\right]$ and Blocks [Wilks' lambda $=0.590, \mathrm{~F}(3,117)=27.1, \mathrm{p}$ $\left.<0.001, \eta_{\mathrm{p}}^{2}=0.41\right]$. In the measurement of the Total Reaction Time (TRT) there was a significant difference between Blocks for both SD groups (block 1: 2333 $\pm 1267 \mathrm{~ms}$; block 2: $1741 \pm 1279 \mathrm{~ms} ; \mathrm{p}<0.001$ ), demonstrating a greater capacity to react to a stimulus to a lesser extent time. We can conclude that people with DS improved their performance during the practice in virtual tasks, in this way, these games can contribute to motor learning of these individuals.
\end{abstract}

Keywords: Down Syndrome, Motor Skills. Virtual Reality. 


\section{LISTA DE FIGURAS}

Figura 1- Fluxograma de seleção grupo de Síndrome de Down.

Figura 2 - Tela inicial de apresentação do Check Limits, com bolas dispostas em linhas e

colunas.

Figura 3 - Tela de apresentação do Check Limitis: Alcance das bolas (câmera Kinect

Figura 4 - .Representação gráfica do posicionamento correto durante a execução do teste

utilizando o Check Limits com a câmera Kinect.

Figura 5 - Tarefa de Timing Coincidente: Demonstração da execução.

Figura 6A - Tarefa de Timing Coincidente - Demonstração da execução errada. 6B - Tarefa de Timing Coincidente - Demonstração da execução correta.

Figura 7 - Tela de apresentação do Tempo de Reação Total Simples ..................................... 22

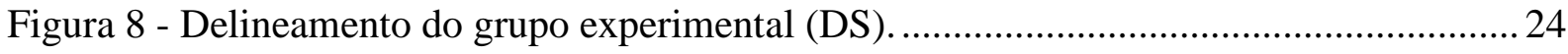

Figura 9 - Representação das tentativas em cada jogo. .........................................................24

Figura 10 - Quantidade de bolhas alcançadas em cada tentativa da tarefa. Além disso, são apresentadas a melhor e pior tentativa de todos os participantes.

Figura 11 - Erro constante (ms) para grupos (SD, DT) e blocos para todas as fases do estudo.

Os valores representados como média e erros padrão

Figura 12 - Erro absoluto (ms) para grupos (SD, DT) e blocos para todas as fases do estudo. Os valores representados como média e erros padrão. $3 \underline{0}$

Figura 13 - Erro variável (ms) para grupos (SD, DT) e blocos para todas as fases do estudo. Os

valores representados como média e erros padrão.

Figura 14 - Desempenho na tarefa Tempo de Reação do grupo SD e DT, no bloco 1 (média das 7 primeiras tentativas) e no bloco 2 (média das 7 últimas Tentativas) 


\section{LISTA DE TABELAS}

Tabela 1 - Caracterização da amostra do grupo SD.........................................................26

Tabela 2 - Caracterização do perfil de conhecimento tecnológico do grupo SD..............27

Tabela 3 - Caracterização das Habilidades do grupo SD.................................................27 


\section{LISTA DE ABREVIATURAS}

APAE

CAAE

DP

DSM

DT

EA

EACH- USP

EC

EV

$\mathrm{K}$

LSD

M

MIF

MR

ms

QI

$\mathrm{R}$

RV

S

SD

$\mathrm{T}$

TALE

TCLE

TEA

TRT_S

WASI
Associação de Pais e Amigos dos Excepcionais

Certificado de Apresentação e Apreciação Ética

Desvio Padrão

Diferença de Significância Mínima

Desenvolvimento Típico

Erro Absoluto

Escola de Artes, Ciências e Humanidades da Universidade

de São Paulo

Erro Constante

Erro Variável

Kinect

Diferença de Significância Menor

Média

Medida de Independência Funcional

Medidas Repetidas

milissegundos

Quociente de Inteligência

Retenção

Realidade Virtual

Segundos

Síndrome de Down

Transferência

Termo de assentimento livre esclarecido

Termo de Consentimento Livre e Esclarecido

Transtorno do Espectro Autista

Tempo de Reação Total Simples

Escala de Inteligência Weschsler Abreviada 


\section{SUMÁRIO}

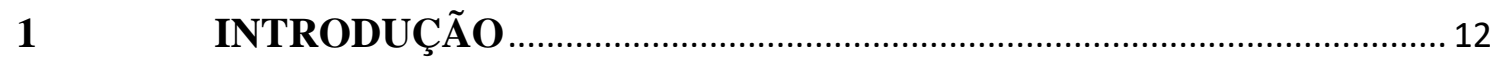

2 OBJETIVO

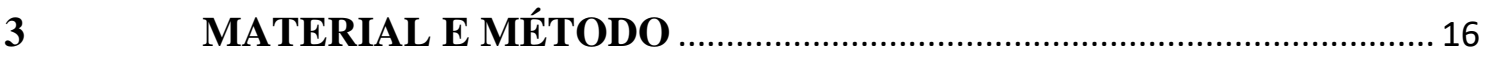

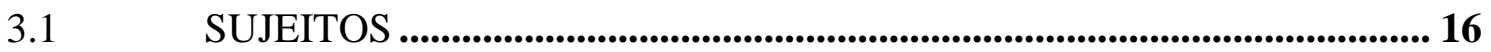

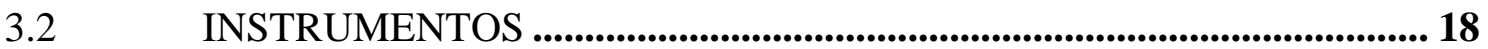

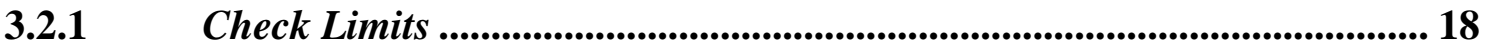

3.2.2 Timing Coincidente Virtual ......................................................................... 20

3.2.3 Tempo de Reação Total Simples (TRT_S) .............................................. 22

3.3 PROCEDIMENTOS................................................................................................... 23

3.3.1 Protocolo Experimental ............................................................................ 23

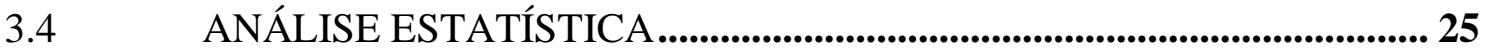

$4 \quad$ RESULTADOS

C.1 CARACTERIZAÇÃO DA AMOSTRA ......................................................... 26

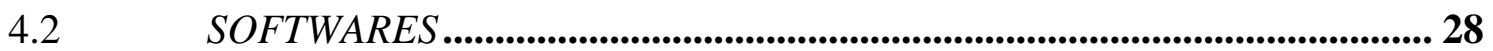

4.2.1 Check Limits .................................................................................................... 28

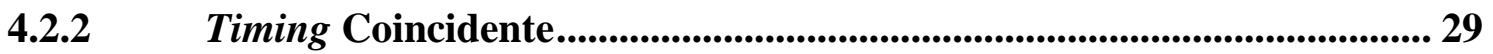

4.2.2.1 Aquisição ..................................................................................................... 29

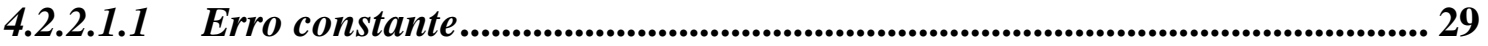

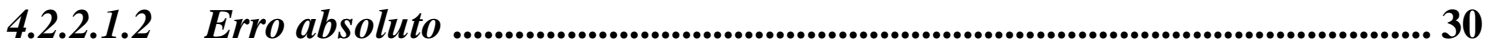

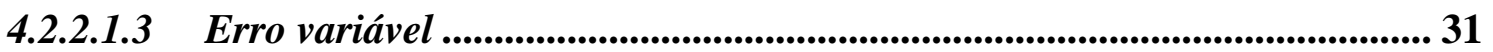

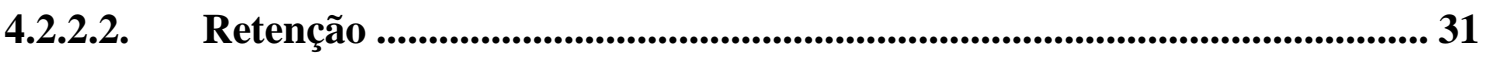

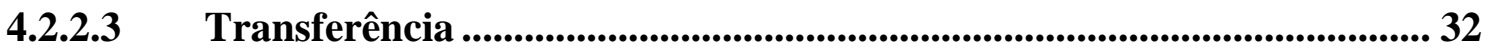

4.2.2.3.1 Erro constante ......................................................................................................... 32

4.2.2.3.2 Erro absoluto ............................................................................................................ 32

4.2.2.3.3 Erro variável ................................................................................................ 33

4.2.3 Tempo de Reação Total Simples ............................................................. 33

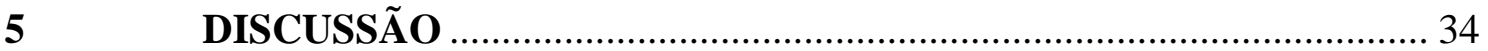

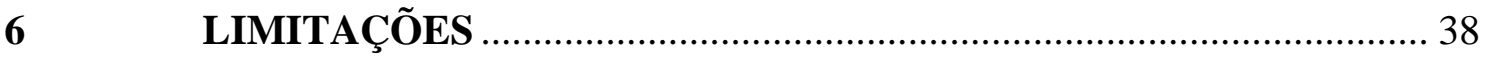

7 CONCLUSÃO

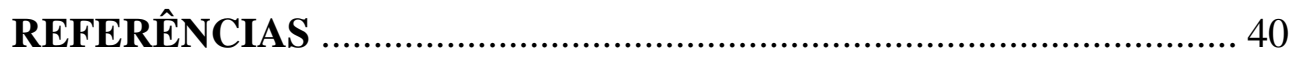

ANEXO A..........................................................44

ANEXO B.............................................................49 
ANEXO C.............................................................52

ANEXO D.........................................................54

ANEXO E..............................................................55 


\section{INTRODUÇÃO}

A síndrome de Down (SD) é a condição genética mais comum de deficiência intelectual e é causada pela trissomia do cromossomo 21 (ANTONARAKIS et al., 2020), geralmente devido à não disjunção ou falha dos cromossomos homólogos ou cromatídeos irmãos em se separarem adequadamente durante a divisão celular (RAFII et al., 2019). Pode-se identificar trissomia simples em $\approx 95 \%$ dos casos, mosaico em $\approx 1-2 \%$, e translocação do cromossomo em $\approx 3-4 \%$ (MORRIS et al., 2012).

Estima-se uma incidência mundial entre 1/700 à 1/1000 nascidos vivos (HUGHESMCCORMACK et al., 2020) com aumento significativo na expectativa de vida para aproximadamente 50 anos de idade (GENSOUS et al., 2019; ANTONARAKIS et al., 2020) principalmente em decorrência dos avanços em tratamento médico, terapias, inclusão e desempenho social (CHIVIACOWSKY et al, 2013; PRESSON et al., 2013).

A SD está associada a alterações na anatomia corporal, $71 \%$ das anomalias estão presentes na área craniofacial e nas mãos, dentre estas destacam-se a braquicefalia, fissuras palpebrais com inclinação superior, pregas epicânticas, base nasal achatada e pescoço curto. Observa-se anomalias físicas menores que são um ligeiro desvio nas fendas físicas externas, sendo estes: orelhas baixas e displásicas, palato arqueado alto, língua protusa, quinto dedo curvado, prega palmar única e geralmente há uma lacuna entre o $1^{\circ}$ e o $2^{\circ}$ dedo (BHATTACHARYYA, SANYAL e BHATTACHARYYA, 2018; CORNEJO et al., 2017).

O fenótipo da SD envolve manifestações que afetam múltiplos sistemas corporais, em particular os sistemas músculo-esquelético, neurológico e cardiovascular. Indivíduos com SD geralmente apresentam baixa estatura, hipotonia muscular, instabilidade atlantoaxial, densidade neuronal reduzida, hipoplasia cerebelar, incapacidade intelectual e cardiopatias congênitas (CHDs; particularmente defeitos do septo atrioventricular). Os indivíduos com SD também têm maior probabilidade de desenvolver certas condições de saúde, incluindo hipotireoidismo, doenças autoimunes, apneia obstrutiva do sono, epilepsia, problemas de audição e visão, distúrbios hematológicos (incluindo leucemia), infecções recorrentes, distúrbios de ansiedade e doença de Alzheimer precoce (ANTONARAKIS et al., 2020).

Os comprometimentos musculoesqueléticos encontrados podem ser responsáveis pelo atraso da aquisição de marcos no desenvolvimento motor (PEREIRA et al., 2013) com longo tempo de reação a estímulos, movimentos lentos com comprometimento da coordenação, dificuldade para utilização das reações antecipatórias, prejuízo nas reações de equilíbrio, atraso na marcha e déficit no sistema de controle postural, atribuídos a limitações no processamento 
vestibular, ou a um pobre reconhecimento de estímulos proprioceptivos (CARDOSO et al., 2015). Estas alterações motoras e perceptivas resultam em padrões de movimentos atípicos (CHIVIACOWSKY et al, 2012) e disfunção de integração sensorial como resultado da limitada experiência sensorial (WILL et al., 2019). Os padrões atípicos da organização do cérebro podem ser responsáveis por muitas características cognitivas que geram certa dificuldade na aprendizagem, respostas motoras e na organização e percepção (TORRIANI-PASIN et al, 2013).

Todos estes distúrbios associados à SD podem dificultar a funcionalidade e a independência para realizar atividades da vida diária mesmo durante a idade adulta, tornandoas muitas vezes vulneráveis ao aprendizado (DE MELLO MONTEIRO et al, 2017; MENEZES et al., 2015; ZAGO et al., 2020). O nível de comprometimento pode influenciar na capacidade de aprendizagem de um movimento ou tarefa, que está diretamente relacionado com algumas das fases do ciclo perceptivo-motor do processo de aprendizagem motora (MACKENZIE et al., 2009; SILVA, 2013) sendo necessário avaliação e intervenção específica, com equipe multidisciplinar, desde o nascimento até a vida adulta (ALEXANDER et al., 2016).

Uma ferramenta que pode ser útil no suporte ao desenvolvimento global e para a reabilitação de pessoas com SD é a utilização da realidade virtual (RV), considerada uma tecnologia baseada em tecnologia computacional e que fornece um ambiente multissensorial com o qual o usuário pode interagir. O uso da RV na reabilitação possibilita a participação de pessoas com necessidades especiais e oferece uma série de benefícios: (I) repetição de tarefas complexas para favorecer a aprendizagem de habilidades motoras e funcionais direcionadas por estímulos visuais e auditivos que criam interação dinâmica entre o indivíduo e tarefa e tornam a atividade mais empolgante; (II) graduação da complexidade das tarefas de forma a aumentar ou diminuir a carga cognitiva (III) feedback imediato do desempenho e resultados com medidas objetivas dos movimentos (BURDEA, 2003); (IV) maior motivação no ambiente de reabilitação; (V) capacidade de individualizar o tratamento e poder facilmente ser classificada e documentada; (VI) padronização aumentada de protocolos de avaliação e treinamento (ADAMOVICH et al, 2009; MENDES et al, 2012; BERNARDONI et al., 2019).

A RV permite a transferência das habilidades alcançadas durante a prática na reabilitação para funcionalidade no mundo "real" (SVEISTRUP, 2004), com melhoria relativamente permanente do desempenho e facilitação do processo de aprendizagem motora (MENDES et al, 2012), visto que, a prática e a experiência são condições necessárias, embora não suficientes, para que ocorra a aprendizagem (HOLMEFUR et al., 2010; POSSEBOM, 2013). 
A integração bem-sucedida da RV com as variadas formas de reabilitação, contribuem para uma intervenção eficaz (RAND, KIZONY e WEISS, 2004), com um contexto seguro, que enfatiza a participação do indivíduo com motivação e interesse nas atividades propostas. Dessa forma contribui para o alcance de maior desempenho das funções motoras e cognitivas, independência, produtividade e participação em programas acadêmicos e recreacionais, empregos e outras atividades (SVEISTRUP, 2004; JUNIOR e SILVA 2012; MENEZES et al., 2015; TIERI et al., 2018).

Considerando a possibilidade de resultados favoráveis com a utilização de jogos virtuais, este trabalho avaliou o desempenho durante a prática de pessoas com SD e com desenvolvimento típico (DT) em duas tarefas virtuais: Check Limits e Timing Coincidente. Também foi utilizado um software para medir a rapidez com que a pessoa executa uma resposta uniforme a estímulo específico, ou seja, registra o tempo decorrido entre o aparecimento do estímulo e a conclusão da tarefa, chamado de Tempo de Reação Total Simples (TRT_S).

O interesse principal deste trabalho foi avaliar a capacidade de melhora no desempenho em tarefas de timing coincidente e tempo de reação de indivíduos com SD em duas tarefas de realidade virtual e com o software TRT_S respectivamente. De acordo com as observações realizadas, a hipótese é que ocorrerá melhora do desempenho nas diferentes tarefas propostas, com melhora da quantidade de bolas alcançadas no jogo Check Limits, melhora do timing coincidente durante a aquisição (além da capacidade para manter o desempenho para a fase de retenção e transferência) e a melhora do tempo de reação total. 


\section{OBJETIVO}

Analisar a melhora do desempenho em tarefas de realidade virtual utilizando três softwares computacionais: Check Limits, Timing Coincident e o Tempo de Reação Total em pessoas com Síndrome de Down. 


\section{MATERIAL E MÉTODO}

Este estudo foi aprovado pelo comitê de ética em pesquisa da Universidade de São Paulo (CAAE: 86979418.8.0000.5390).

\subsection{SUJEITOS}

Para a realização deste trabalho foram avaliadas 122 pessoas, divididas em dois grupos: 61 pessoas com diagnóstico de Síndrome de Down (grupo SD), com idade entre 8 e 50 anos, 61 pessoas com desenvolvimento típico (grupo DT), pareados por idade e sexo ao grupo SD. Para tanto, o grupo com SD foi avaliado na APAE - Associação de Pais e Amigos dos Excepcionais de Vila Velha e Vitória - instituição especializada no atendimento a pessoas com deficiência intelectual e /ou múltipla e /autismo.

Como critério de inclusão, consideramos: (1) a assinatura do termo de consentimento livre e esclarecido (TCLE) pelos pais ou responsáveis pelos menores (ANEXO I); (2) termo de assentimento livre esclarecido (TALE) pelo menor (ANEXO II); (3) para o grupo SD foram avaliados pessoas com deficiência intelectual leve e moderado diagnosticados por neurologista infantil e equipe multidisciplinar da instituição por meio de histórico do paciente; (4) com idade acima de 8 anos; (5) somente foram incluídos pessoas que compreenderam as orientações em relação a tarefa proposta em cada jogo (avaliado por meio da capacidade do participante executar corretamente a tarefa após realizar três tentativas com explicação e demonstração do avaliador).

Para esse estudo foram excluídas pessoas com SD com deficiência intelectual grave, comorbidades como Transtorno do Espectro Autista (TEA), deficiências funcionais que impedissem a realização da tarefa, quadro álgicos em membros superiores, além de desistência durante o protocolo. (8 pessoas foram excluídas por apresentar deficiência intelectual grave, 3 pessoas foram excluídas por incompreensão da tarefa e 1 pessoa foi excluída por não finalizar o protocolo) - ver fluxograma figura 1. 
Figura 1- Fluxograma de seleção grupo Síndrome de Down

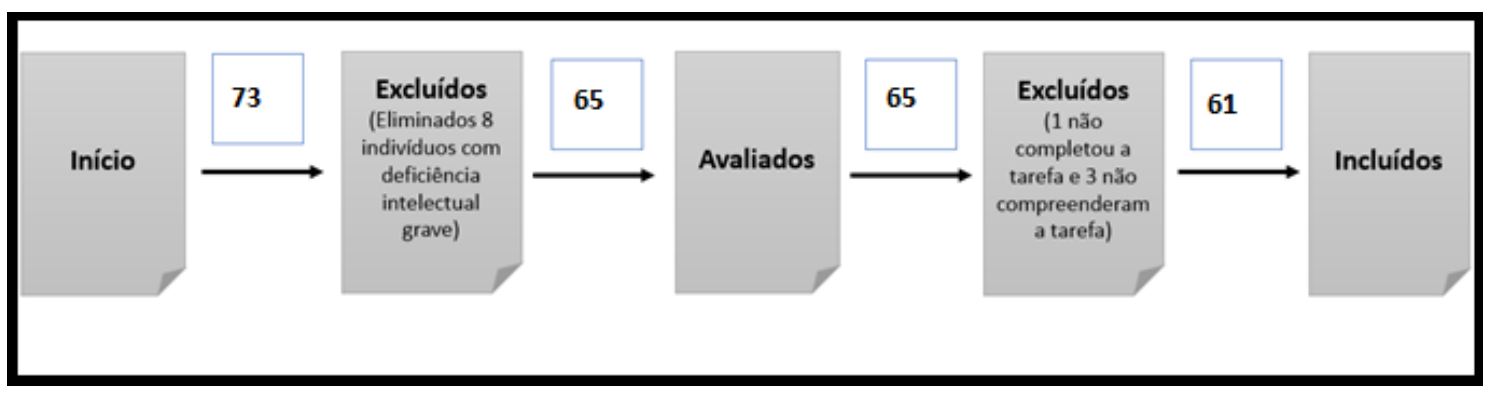

Fonte: Maely Pedrosa Pimentel, 2020.

Para caracterização da amostra foi aplicado questionário do perfil sociodemográfico, tecnológico e condições motoras, adaptado de TRIGUEIRO et al, 2011; FERREIRA e WAGNER, 2012; MANSUR e MARCON, 2006 (ANEXO III). Este questionário contém 33 questões no total, sendo que 10 questões buscam identificar características sociodemográficas, 6 questões sobre o perfil tecnológico dos indivíduos, 7 questões voltadas para condições motoras e 10 questões de saúde geral (fala, linguagem, função auditiva e visual, interesse, interação e uso de medicamentos controlados).

Para a caracterização clínica, foi aplicada a Medida de Independência Funcional (MIF) (ANEXO IV) (RIBEIRO et al, 2004), é um instrumento que tem o objetivo principal avaliar quantitativamente a carga de cuidados demandada para a execução de diversas tarefa motoras e cognitivas. As atividades avaliadas foram descritas em 18 itens, agrupados em seis dimensões: autocuidado, locomoção, transferência, comunicação, controle dos esfíncteres e cognição social. Cada item pode receber pontuação de 1 a 7 , correspondendo, respectivamente, à dependência total e à independência completa. O escore total da MIF é dado pela soma dos escores de cada dimensão e sua pontuação total pode variar de 18 a 126, e cada dimensão é analisada pela soma dos itens que a compõem. Os níveis de dependência são classificados de acordo com o escore total da MIF: 18: dependência completa; 19 a 60: dependência modificada (assistência de até 50\% das tarefas); 61 a 103: dependência modificada (assistência de até 25\% das tarefas); e 104 a 126: independência completa/modificada (ASSIS et al, 2015).

Também foi utilizada a versão adaptada da Escala de Inteligência Wechsler Abreviada (WASI) (ANEXO V). A WASI é um instrumento de avaliação breve da inteligência, é composta por quatro subtestes, sendo dois Verbais (Vocabulário e Semelhanças) e dois de Execução (Cubos e Raciocínio Matricial), e sua aplicação destina-se a sujeitos de 6 a 89 anos. Os quatro subtestes fornecem o Quociente de Inteligência (QI) da escala Total que avalia o nível geral do funcionamento intelectual, o QI Verbal é fornecido pela soma dos subtestes de 
Vocabulário e Semelhanças e avalia os processos verbais e de conhecimento adquirido, o QI de Execução é dado pela soma dos subtestes de Cubos e Raciocínio Matricial e mede a organização perceptual, capacidade de manipular estímulos visuais com velocidade (YATES et al, 2006; HECK et al, 2009). As faixas correspondentes aos valores de QI são: Abaixo de 69: Muito Rebaixado; 70 à 79: Limítrofe; 80 à 89: Médio Inferior; 90 à 109: Média; 110 à 119: Médio Superior; 120 à 129: Superior; Acima de 130: Muito Superior (NOFFS et al., 2006).

\subsection{INSTRUMENTOS}

Para a coleta de dados, utilizou-se três softwares de jogos desenvolvidos em parceria com o grupo de Sistemas de Informação da Escola de Artes, Ciências e Humanidades da Universidade de São Paulo - EACH-USP.

\subsubsection{Check Limits}

Este jogo apresenta um conjunto de 96 bolhas em 3D, dispostas em linhas e colunas (Figura 2). Para este estudo optou-se por utilizar a câmera Kinect e a meta do participante consistiu em alcançar o maior número de bolas (visualizado pela mudança de cor), ou seja, menor número de Remaining Bubbles e maior número de pontos em um tempo determinado de 15 segundos (Figura 3 e 4 ).

Foram registrados pelo software as bolas alcançadas, média de tempo, tempo máximo e tempo mínimo, em milissegundos e objetivo foi avaliar a diferença da quantidade de bolas alcançadas em cada tentativa.

O Check Limits é uma tarefa que permite avaliar diversos aspectos, como; organização espacial, planejamento da ação, e execução de movimento para alcançar um objetivo virtual (CROCETTA et al., 2018). 
Figura 2 - Tela inicial de apresentação do Check Limits, com as bolhas dispostas em linha e colunas.

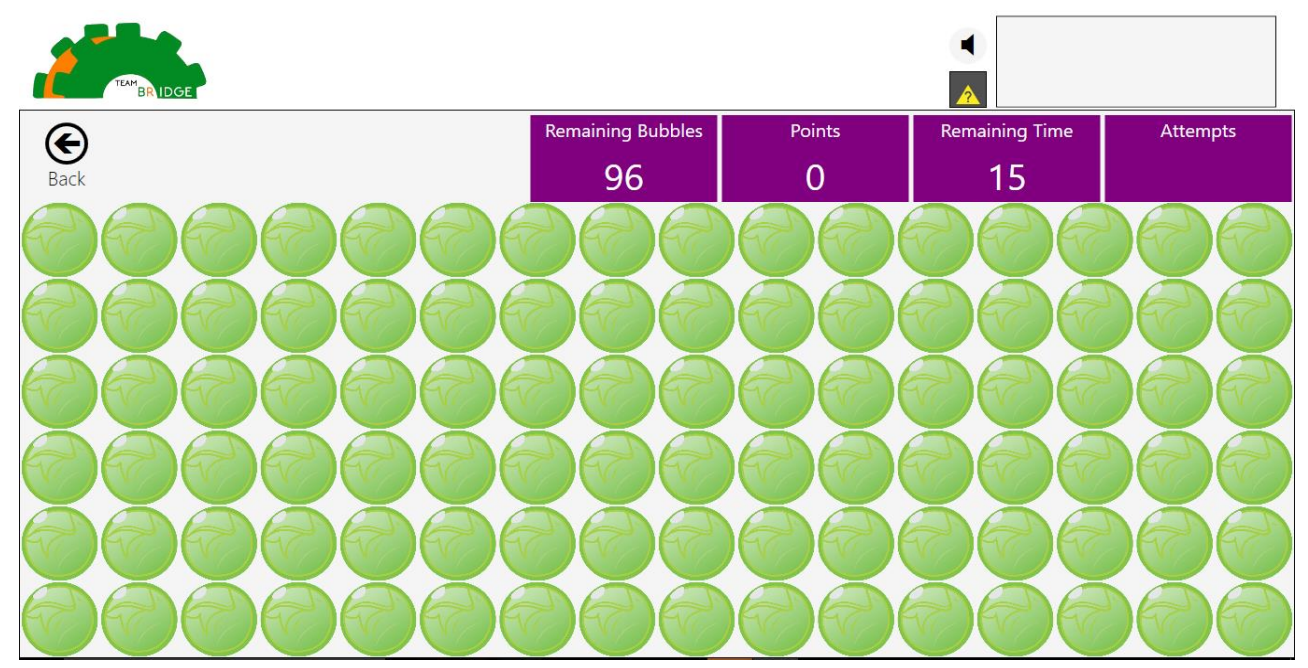

Fonte: Maely Pedrosa Pimentel, 2020.

Figura 3 - Tela de apresentação do Check Limits: Alcance das bolas (câmera Kinect).

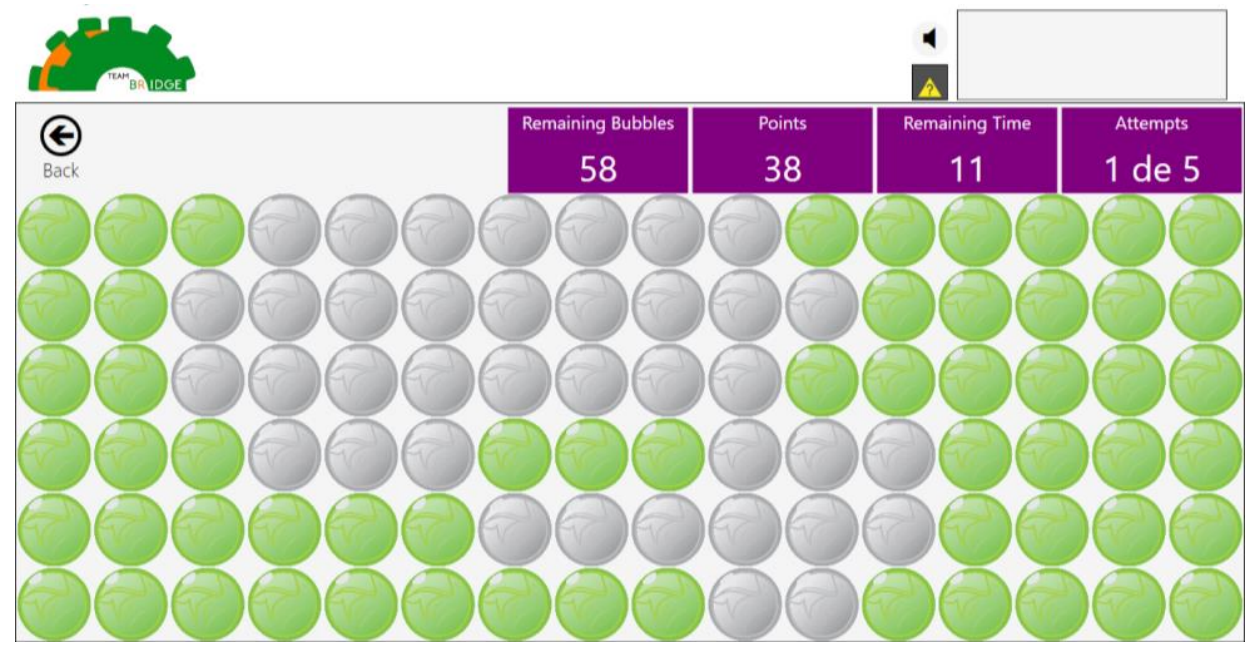

Fonte: Maely Pedrosa Pimentel, 2020. 
Figura 4 - Representação gráfica do posicionamento correto durante a execução do teste utilizando o Check Limits com a utilização da câmera Kinect.

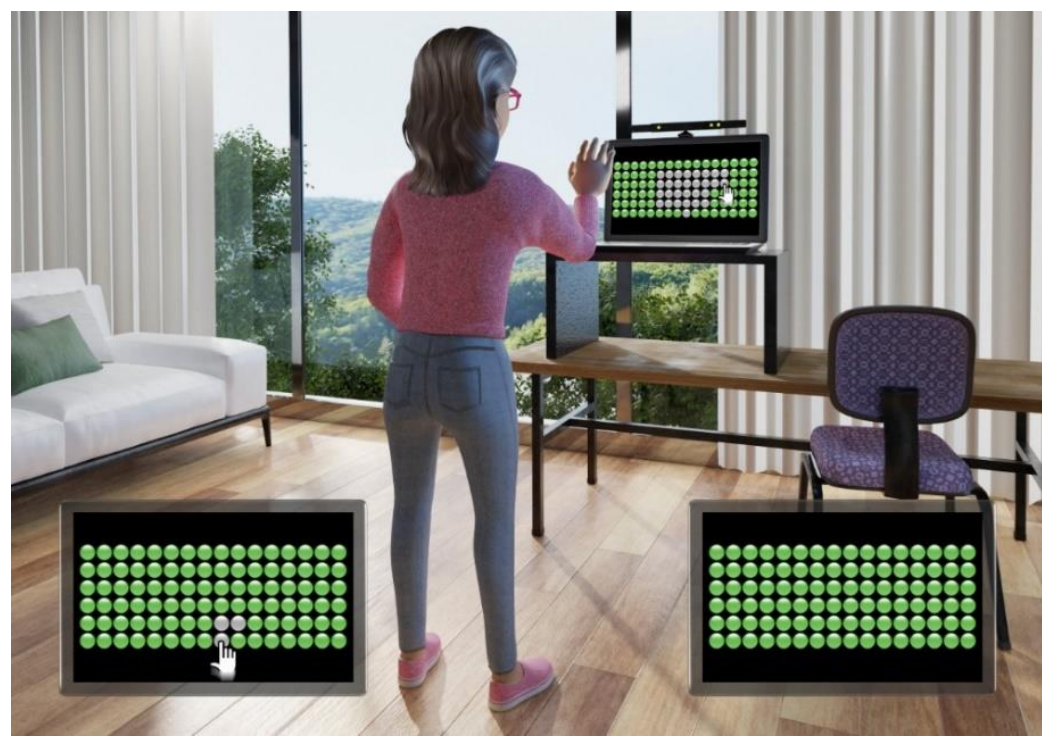

Fonte: Maely Pedrosa Pimentel, 2020.

\subsubsection{Timing Coincidente Virtual}

A tarefa de timing coincidente consiste em atingir um alvo com a mão no mesmo instante de chegada de um objeto em movimento (FORNER-CORDERO et al. 2017). O jogo utilizado ofereceu uma tarefa de Timing Coincidente com 10 bolas em 3D que acendem (luz vermelha) em sequência até atingir a última bola considerada o alvo (Figura 5), os participantes foram orientados a apertar a tecla de espaço no computador concomitantemente com o acendimento da bola alvo (a última bola). O software fez a captação do tempo em milissegundos de acerto ou erro no toque ou movimento da mão e ofereceu um feedback imediato de acerto ou erro da tarefa por meio de sons e cores diferentes, previamente demonstrados. Quando o participante acertava o alvo no mesmo momento da chegada do estímulo, uma luz verde acendia ao redor da tarefa - feedback de acerto (Figura 6B), no entanto caso o participante atrasasse ou adiantasse o movimento, uma luz vermelha acendia ao lado da tarefa - feedback de erro (Figura $6 \mathrm{~A})$.

Foram registradas pelo software, em milissegundos, a magnitude e a direção do erro de cada participante ao antecipar ou atrasar a "chegada" da luz ao alvo. O objetivo foi avaliar a diferença de tempo entre a execução da resposta do participante e a chegada do objeto no local de destino, a precisão temporal global e, portanto, a habilidade de coincidência-antecipação de tempo. 
O software forneceu um nome de usuário para cada participante da pesquisa, onde os seguintes dados foram armazenados: nome do participante; data de nascimento; sexo; doença; nome do pesquisador (CROCETTA et al., 2018).

Figura 5 - Tarefa de Timing Coincidente - Demonstração da execução.

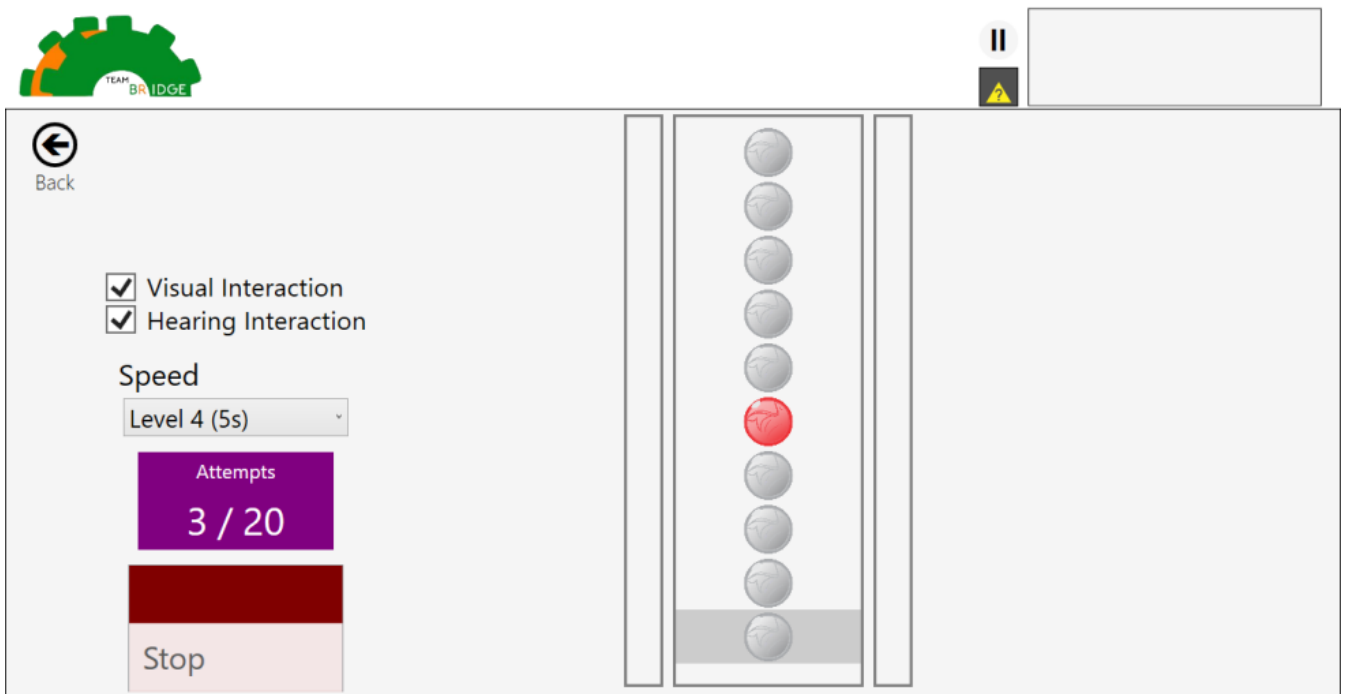

Fonte: Maely Pedrosa Pimentel, 2020.

Figura 6A - Tarefa de Timing Coincidente - Demonstração da execução errada. 6B - Tarefa de Timing Coincidente - Demonstração da execução correta.

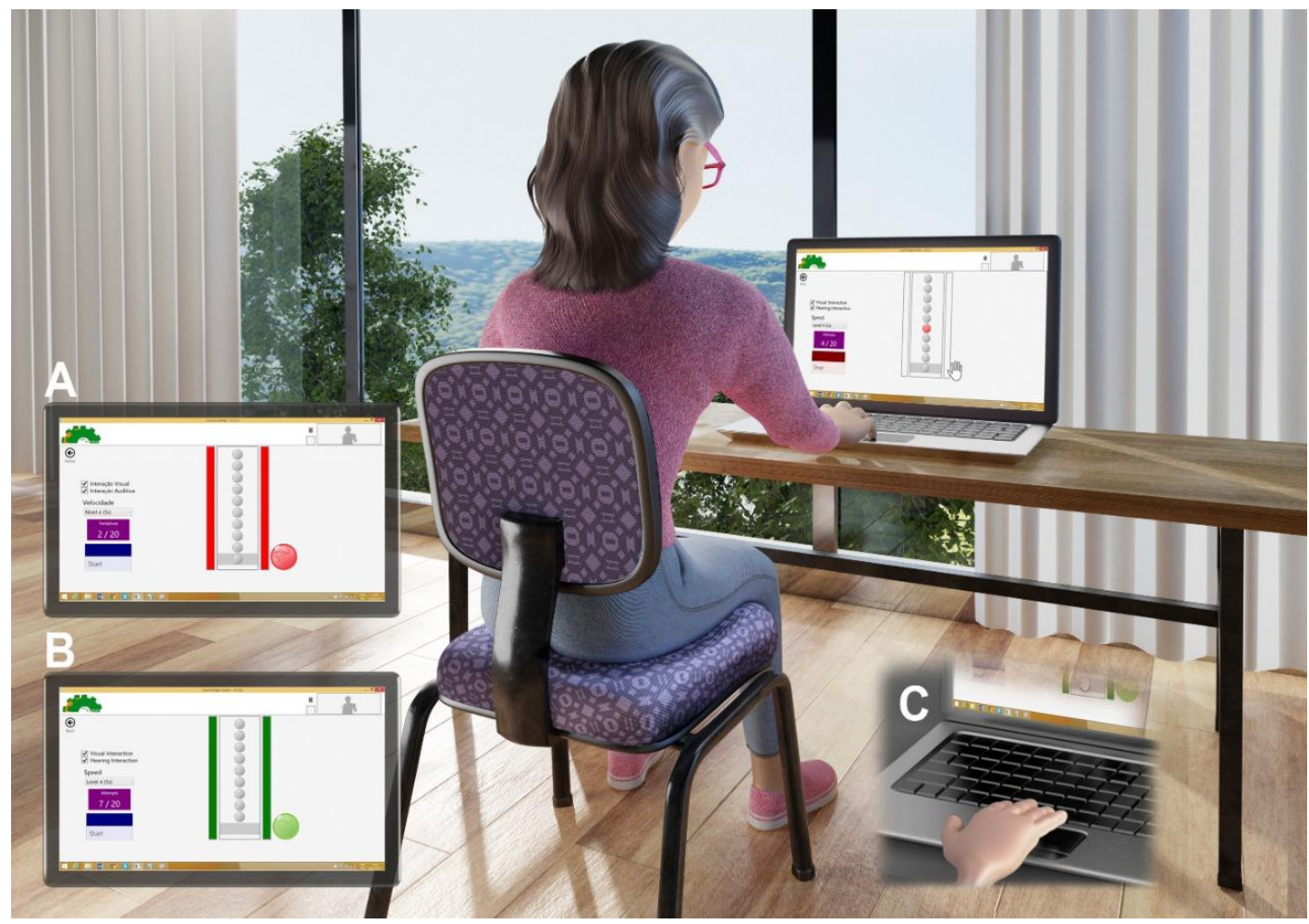

Fonte: Maely Pedrosa Pimentel, 2020. 


\subsubsection{Tempo de Reação Total Simples (TRT_S)}

O tempo de Reação Total é a medida da velocidade com que o indivíduo efetua uma resposta uniforme a um estímulo específico (ECKNER et al., 2012). O software Tempo de Reação Total Simples (TRT_S), envolve a identificação do estímulo, a interpretação, preparação da resposta e a efetiva ação motora (ZWIERKO et al, 2010), ou seja, é o intervalo de tempo entre o estímulo e a conclusão da tarefa (CROCETTA et. al., 2017).

Poder mensurar o tempo de reação é importante para verificar o desempenho em diversas tarefas, sejam elas esportivas, profissionais ou atividades da vida diária. Um tempo de reação longo pode comprometer a ação do indivíduo caso a tarefa exija dele uma resposta imediata ao estímulo que lhe foi apresentado (SANCHEZ, PINZON e ZHENG, 2017). O objetivo da utilização deste software neste trabalho foi reunir dados que reportem a possibilidade de melhora do tempo de reação durante a execução de um jogo com 14 repetições.

Este Software propõe um teste que consistiu no aparecimento de um quadrado amarelo (parametrizável) no centro do monitor em intervalos de tempo previamente definidos (variando de 1,5 a $6,5 \mathrm{~ms}$ ) e, quando o estímulo aparecia, o participante deveria reagir o mais rapidamente possível, pressionando a barra de espaço do teclado do computador (Figura 7).

O software forneceu um nome de usuário para cada participante da pesquisa, onde os seguintes dados foram armazenados: nome do participante; data de nascimento; sexo; idade e data da aplicação do teste.

Figura 7. Tela de apresentação do Tempo de reação simples.

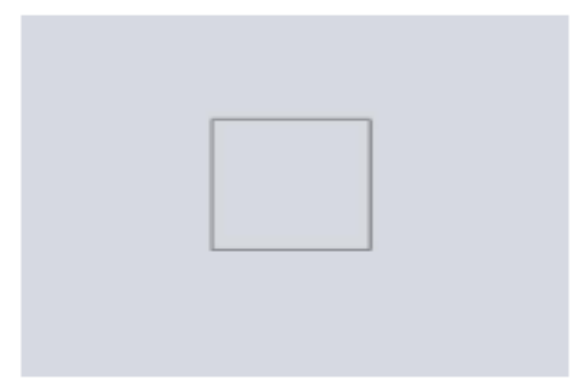

(A)

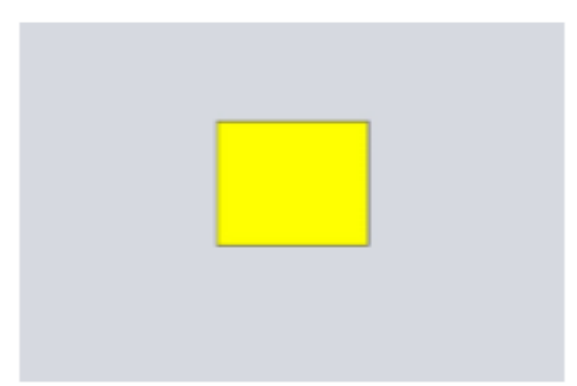

(B)

Fonte: Maely Pedrosa Pimentel, 2020. 


\subsection{PROCEDIMENTOS}

Foi realizado um levantamento dos prontuários de todos os indivíduos que apresentam diagnóstico de Síndrome de Down (SD) da APAE de Vitória e Vila Velha, para seleção de acordo com a idade, grau de comprometimento cognitivo e possível comorbidades associadas. Os responsáveis foram informados quanto ao desenvolvimento do estudo, objetivos, hipóteses, resultados esperados e após apresentação do protocolo foi apresentado o Termo de Consentimento Livre e Esclarecido (TCLE) e o Termo de Assentimento Livre Esclarecido (TALE) para assinatura.

Previamente à realização das tarefas em Realidade Virtual (RV), foi aplicado questionário do perfil sociodemográfico, tecnológico e condições motoras, e a Medida de Independência Funcional (MIF), ambos foram realizados com o responsável do participante da pesquisa, também foi aplicada a Escala de Inteligência Wechsler Abreviada (WASI) para posterior correlação, durante a análise dos dados. Para a realização do protocolo de tarefa virtual foi agendado novo encontro.

\subsubsection{Protocolo Experimental}

Os participantes realizaram as tarefas individualmente em uma sala silenciosa, somente com o experimentador, que forneceu as instruções verbais. Antes de iniciar a tarefa, mostrouse o funcionamento através da demonstração do jogo e foi informado o momento de iniciar a partir do comando verbal "prepara", fornecido pelo experimentador.

Para a realização do Check Limits, os indivíduos foram posicionados em pé em frente ao computador colocado sobre uma mesa, a distância foi determinada de acordo com cada pessoa, considerando o melhor posicionamento entre o computador, a pessoa e o Kinect. Para a realização do Timing coincidente e o Tempo de Reação Total (TRT) o participante ficou sentado em uma cadeira ajustada de acordo com o tamanho e necessidade, assim como o apoio para os pés, de tal forma que ficasse posicionado adequadamente para viabilizar o início e a finalização da tarefa.

O protocolo de aprendizagem motora foi organizado por meio de blocos de 5 tentativas cada nos dois primeiros jogos (Check Limits e Timing coincidente) e blocos de 7 tentativas cada, no último jogo (TRT) para garantir a equidade na avaliação do desempenho dos participantes. Todos os participantes realizaram as mesmas etapas do protocolo (veja figura 8). 
Figura 8 - Delineamento do grupo experimental (SD)

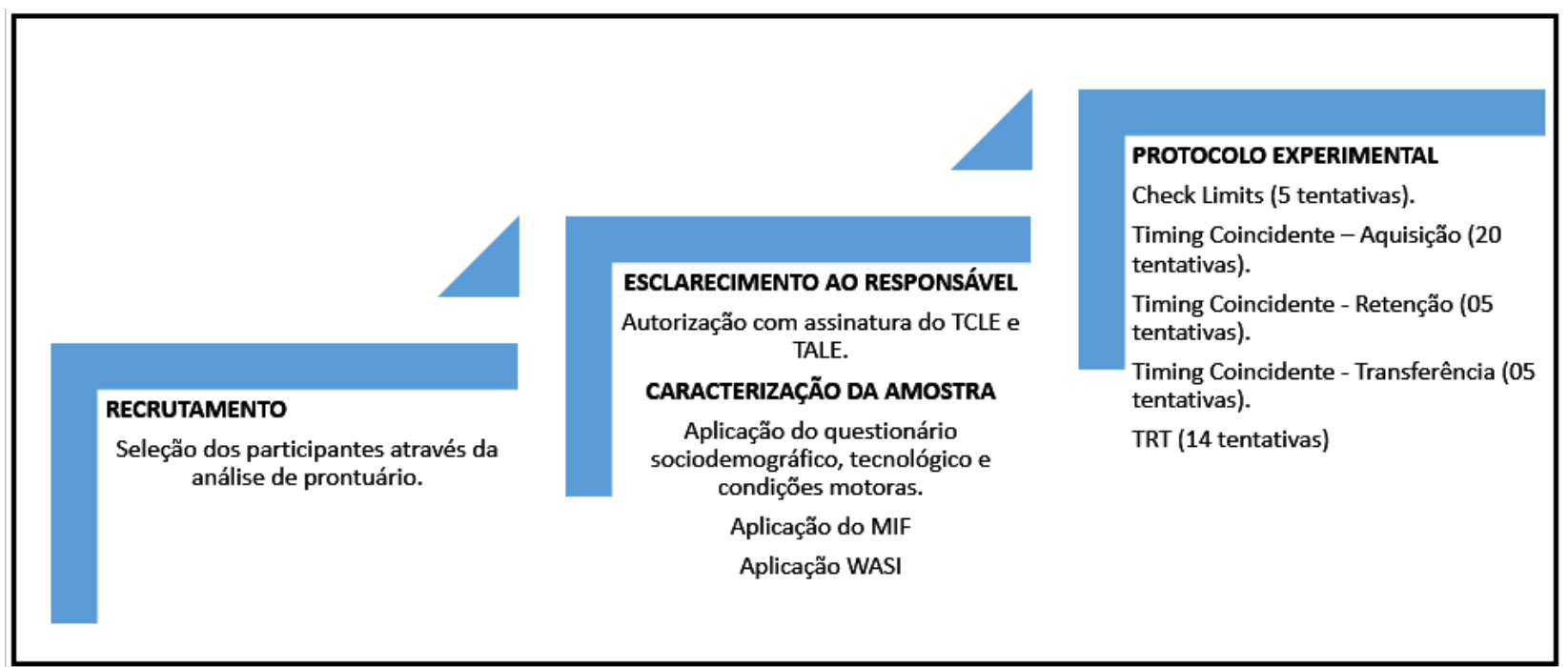

Fonte: Maely Pedrosa Pimentel, 2020.

O primeiro jogo o Check Limits, cada indivíduo realizou 5 tentativas, com a utilização de um ou dos dois membros superiores. No segundo jogo, Timing Coincidente, fizeram 20 tentativas na aquisição (divididas em 04 blocos), 5 tentativas na retenção (teste após 5 minutos sem contato com a tarefa), 5 tentativas na transferência (realizada em tarefa com aumento de velocidade do jogo), totalizando 30 repetições. No terceiro jogo, TRT, cada indivíduo realizou 14 tentativas (divididas em 2 blocos de 7 tentativas) da tarefa foi realizada com o membro superior dominante. Veja Figura 9.

Figura 9 - Representação das tentativas em cada jogo.

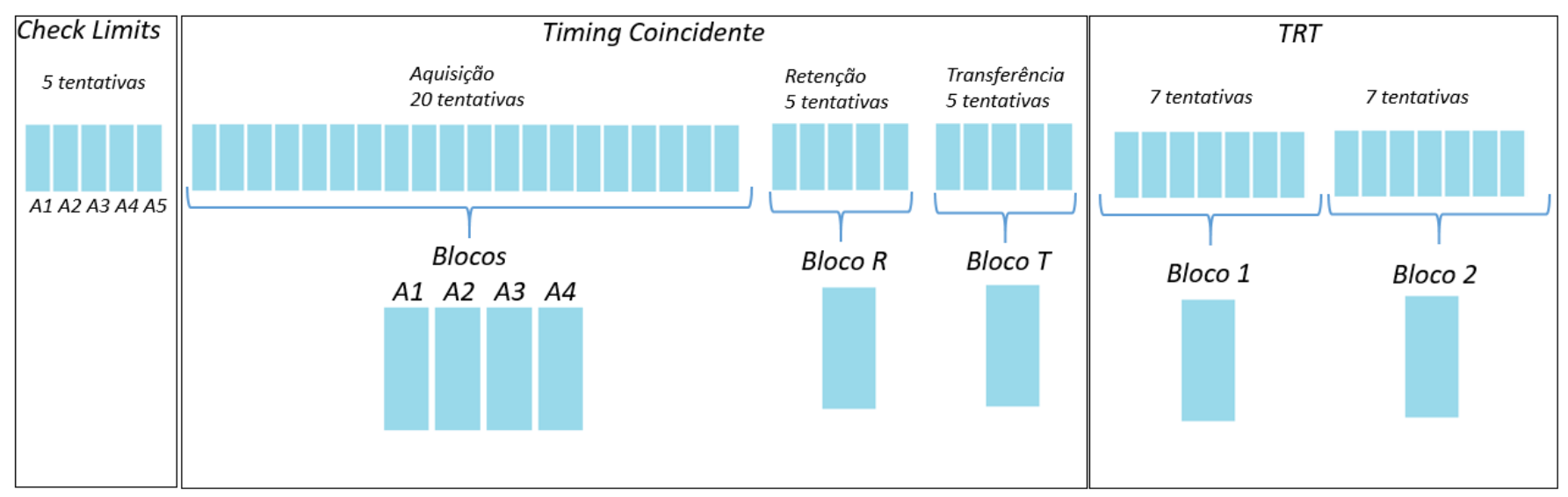

Fonte: Maely Pedrosa Pimentel, 2020. 


\subsection{ANÁLISE ESTATÍSTICA}

No Check Limits as variáveis dependentes utilizadas foram a quantidade de bolhas alcançadas em cada tentativa da tarefa. Para comparação, as variáveis dependentes foram submetidas a ANOVA com fator 2 (grupo: SD, DT) por 2 (tentativas) com medidas repetidas (MR) sobre o último fator. Para o fator tentativas, foram feitas comparações separadas para primeira tentativa (1) versus quarta tentativa (4) e primeira tentativa (1) versus última tentativa (5). Para melhor e pior tentativa, usamos um teste $t$ de amostra independente para comparar o grupo SD e DT. A parcial $\eta^{2}$ foi usado para calcular o tamanho do efeito, onde $\eta p^{2}=0,01$ foi considerado um pequeno efeito, $\eta p^{2}=0,06$ moderado efeito e $\eta p^{2}=0,14$ grande efeito (SILVAFILHO, 2018). Comparações post hoc foram realizadas usando o teste de Diferença de Significância Mínima - DSM ( $\mathrm{p}<0,05)$.

Considerando a tarefa Timing Coincidente, os resultados foram obtidos utilizando blocos (média de cinco tentativas cada) para todas as fases do estudo (aquisição, retenção e transferência). Essa abordagem foi adotada para minimizar o impacto de valores individuais variáveis (MALHEIROS et al., 2016). As variáveis dependentes utilizadas foram erros de temporização, ou seja, erro constante (EC), erro absoluto (EA) e erro variável (EV). O erro foi definido como a diferença de tempo entre a hora em que a bolha de destino acendia (horário de chegada) e a hora em que o teclado foi tocado. As variáveis dependentes foram submetidas a MANOVA com fator 2 (grupo: SD, DT) por 2 (blocos) com medidas repetidas (MR) no último fator blocos. Para o fator bloco, foram feitas comparações separadas para aquisição (primeiro bloco de aquisição A1 versus bloco de aquisição final A4), retenção (A4 versus bloco de retenção R) e transferência (A4 versus bloco de transferência T).

Considerando a tarefa Tempo de Reação Total Simples (TRT_S) a variável dependente utilizada foi o tempo em milissegundos para completar a tarefa, as 14 tentativas foram divididas em 2 blocos com média de 7 tentativas cada (blocos 1 e 2). A fim de comparar a melhora do bloco 1 para o bloco 2, em ambos os grupos foi utilizado o teste $t$ de amostra pareado e para comparar as diferenças entre os blocos do grupo SD e DT foi utilizado o teste $t$ para amostras independentes.

Os dados contínuos são mostrados como média e barras de erros padrão nos gráficos desvios-padrão dentro do texto escrito. 


\section{RESULTADOS}

\subsection{CARACTERIZAÇÃO DA AMOSTRA}

No total, 122 indivíduos participaram deste estudo, 61 no grupo Síndrome de Down (SD) e 61 no grupo Desenvolvimento Típico (DT), pareados por idade e sexo com o grupo SD. Na Tabela 1 será apresentado a caracterização da amostra do grupo SD, contendo a Medida de Independência Funcional (MIF) e a Escala de Inteligência Wechsler Abreviada (WASI), e o perfil de conhecimento tecnológico na Tabela 2.

Tabela 1 - Caracterização da amostra do grupo SD.

\begin{tabular}{|c|c|c|c|c|}
\hline \multicolumn{2}{|c|}{$\mathrm{n}$ total $=61$} & $\mathbf{n}$ & $\%$ & $\mathrm{M} \pm \mathrm{DP}$ \\
\hline \multirow{3}{*}{ Idade } & 8 à 20 anos & 21 & $(34,42)$ & \multirow{4}{*}{$23,6 \pm 9,3$} \\
\hline & 21 à 30 anos & 30 & $(49,18)$ & \\
\hline & 31 à 40 anos & 8 & $(13,11)$ & \\
\hline \multirow{3}{*}{ Sexo } & $>41$ anos & 2 & $(3,27)$ & \\
\hline & Feminino & 23 & $(37,70)$ & \multirow{2}{*}{--} \\
\hline & Masculino & 38 & $(62,29)$ & \\
\hline \multicolumn{2}{|c|}{ n total $=39$} & $\mathbf{n}$ & $\%$ & $\mathrm{M} \pm \mathrm{DP}$ \\
\hline \multirow{3}{*}{ Escolaridade } & Ensino Especial & 12 & $(30,77)$ & \multirow{3}{*}{--} \\
\hline & Ensino Fundamental & 9 & $(23,08)$ & \\
\hline & Ensino Médio & 18 & $(46,15)$ & \\
\hline Estado Civil & Solteiro & 39 & $(100,0)$ & -- \\
\hline \multirow{2}{*}{ Lado dominante } & Direita & 29 & $(74,36)$ & \multirow{2}{*}{--} \\
\hline & Esquerda & 10 & $(25,64)$ & \\
\hline \multirow{2}{*}{ Uso de medicamentos } & Sim & 21 & $(53,85)$ & \multirow{2}{*}{--} \\
\hline & Não & 18 & $(46,15)$ & \\
\hline \multicolumn{2}{|c|}{$n$ total $=48$} & $\mathbf{n}$ & $\%$ & $\mathrm{M} \pm \mathrm{DP}$ \\
\hline \multirow{3}{*}{ MIF classificação } & Dependência modificada & & & \multirow{3}{*}{$\begin{array}{c}107,7 \pm \\
10,1\end{array}$} \\
\hline & (25\% de assistência) & 11 & $(22,92)$ & \\
\hline & Independente & 31 & $(64,58)$ & \\
\hline \multicolumn{2}{|c|}{$\mathrm{n}$ total $=\mathbf{5 0}$} & $\mathbf{n}$ & $\%$ & $\mathbf{M} \pm \mathrm{DP}$ \\
\hline WASI & QI muito rebaixado < 69 & 50 & $(100,0)$ & $42,5 \pm 3,5$ \\
\hline
\end{tabular}

n: quantidade de avaliados em cada sessão; M: média; DP: desvio padrão. 
Tabela 2 - Caracterização do perfil de conhecimento tecnológico do grupo SD

\begin{tabular}{|c|c|c|c|}
\hline \multicolumn{2}{|c|}{$n$ total $=39$} & \multirow{2}{*}{$\begin{array}{l}\mathbf{n} \\
5\end{array}$} & \multirow{2}{*}{$\frac{\%}{(12,82)}$} \\
\hline & $<2$ anos & & \\
\hline Há quanto tempo faz uso do & entre 2 e 5 anos & 13 & $(33,33)$ \\
\hline \multirow[t]{2}{*}{ computador } & $>5$ anos & 5 & $(12,82)$ \\
\hline & Não soube informar & 16 & $(41,03)$ \\
\hline \multirow{5}{*}{$\begin{array}{l}\text { Nível de experiência com o } \\
\text { computador }\end{array}$} & Bom & 2 & $(5,13)$ \\
\hline & Médio & 12 & $(30,77)$ \\
\hline & Regular & 8 & $(20,51)$ \\
\hline & Ruim & 10 & $(25,64)$ \\
\hline & Nenhum & 7 & $(17,95)$ \\
\hline \multirow{3}{*}{ Horas por dia } & Não usa todo dia & 24 & $(61,54)$ \\
\hline & $<3$ horas & 6 & $(15,38)$ \\
\hline & $>3$ horas & 9 & $(23,08)$ \\
\hline \multirow{4}{*}{ Usa Internet para } & Jogos & 14 & $(35,90)$ \\
\hline & Youtube & 11 & $(28,21)$ \\
\hline & Outros & 12 & $(30,77)$ \\
\hline & Não se aplica & 2 & $(5,13)$ \\
\hline
\end{tabular}

n: quantidade de avaliados nesta sessão.

$\mathrm{Na}$ caracterização do perfil motor e habilidades, todos os participantes apresentaram função auditiva preservada, e a função visual foi corrigida (por meio do uso de óculos) para aqueles que necessitavam, todos realizavam marcha, sem necessidade de apoio, com equilíbrio, sem padrões de estereotipia, porém todos com déficits cognitivos. Nenhum apresentou fraqueza muscular, sensibilidade, ataxia, espasticidade e adormecimento. Demais habilidades são descritas na Tabela 3.

Tabela 3 - Caracterização das Habilidades do grupo SD.

\begin{tabular}{lcccccc}
\hline \multirow{2}{*}{$\mathbf{n}$ n total = 39 } & \multicolumn{2}{c}{ sim } & \multicolumn{2}{c}{ não } & \multicolumn{2}{c}{ às vezes / alguns } \\
\cline { 2 - 7 } & $\mathbf{n}$ & $\mathbf{\%}$ & $\mathbf{n}$ & $\mathbf{\%}$ & $\mathbf{n}$ & \% \\
\hline Escreve & 8 & $(20,51)$ & 31 & $(79,49)$ & 0 & $(0,00)$ \\
Escreve o nome & 18 & $(46,15)$ & 21 & $(53,85)$ & 0 & $(0,00)$ \\
Copia & 19 & $(48,72)$ & 20 & $(51,28)$ & 0 & $(0,00)$ \\
Leitura palavras simples & 5 & $(12,82)$ & 34 & $(87,18)$ & 0 & $(0,00)$ \\
Leitura de frases & 2 & $(5,13)$ & 37 & $(94,87)$ & 0 & $(0,00)$ \\
Identifica números & 11 & $(28,21)$ & 20 & $(51,28)$ & 8 & $(20,51)$
\end{tabular}




\begin{tabular}{|c|c|c|c|c|c|c|}
\hline \multirow[b]{2}{*}{$n$ total $=38$} & \multicolumn{2}{|c|}{ sim } & \multicolumn{2}{|c|}{ não } & \multicolumn{2}{|c|}{ às vezes / alguns } \\
\hline & $\mathbf{n}$ & $\%$ & $\mathbf{n}$ & $\%$ & $\mathbf{n}$ & $\%$ \\
\hline Linguagem Oral & 25 & $(65,79)$ & 0 & $(0,00)$ & 13 & $(34,21)$ \\
\hline Linguagem Não - verbal & 4 & $(10,53)$ & 25 & $(65,79)$ & 9 & $(23,68)$ \\
\hline Escolhe objetos & 36 & $(94,74)$ & 0 & $(0,00)$ & 2 & $(5,26)$ \\
\hline Tem interesse por objetos & 36 & $(94,74)$ & 0 & $(0,00)$ & 2 & $(5,26)$ \\
\hline Simbolismo & 35 & $(92,11)$ & 0 & $(0,00)$ & 3 & $(7,89)$ \\
\hline Ecolalia & 2 & $(5,26)$ & 36 & $(94,74)$ & 0 & $(0,00)$ \\
\hline Interação & 30 & $(78,95)$ & 0 & $(0,00)$ & 8 & $(21,05)$ \\
\hline Diálogo & 22 & $(57,89)$ & 3 & $(7,89)$ & 13 & $(34,21)$ \\
\hline Fala Inteligível & 12 & $(31,58)$ & 5 & $(13,16)$ & 21 & $(55,26)$ \\
\hline
\end{tabular}

n: quantidade de avaliados em cada sessão.

\subsection{SOFTWARES}

Abaixo resultados dos softwares utilizados:

\subsubsection{Check Limits}

Tentativa 1 para tentativa 5 / Tentativa 1 para tentativa 4

A ANOVA mostrou efeitos significativos para as tentativas $[\mathrm{F}(1,119)=12.1, \mathrm{p}=0.001$, $\left.\eta_{\mathrm{p}}{ }^{2}=0.09\right]$ e Grupos $\left[\mathrm{F}(1,119)=85.2, \mathrm{p}<0,001, \eta_{\mathrm{p}}{ }^{2}=0.42\right]$, e uma tendência de interação para tentativas e grupos $\left[\mathrm{F}(1,119)=3.47, \mathrm{p}=0.065, \eta_{\mathrm{p}}{ }^{2}=0.03\right]$. O teste post hoc mostrou que a melhora nas bolhas alcançadas da Tentativa 1 para a Tentativa 4 ocorreu apenas para o grupo SD (35 \pm 2 a 44 \pm 2 , respectivamente; $\mathrm{p}<0.001$ ) (Figura 10). Além disso, o teste $t$ para amostras independentes mostrou que houve diferenças significativas entre os grupos, nas melhores (SD: 54 \pm 16 ; DT: 73 $\pm 10 ; \mathrm{p}<0.001$ ) e piores tentativas (SD: 28 \pm 15 ; DT: $51 \pm 13$; p <0.001) (Figura 10). 
Figura 10 - Quantidade de bolhas alcançadas em cada tentativa da tarefa. Além disso, são apresentadas a melhor e pior tentativa de todos os participantes.

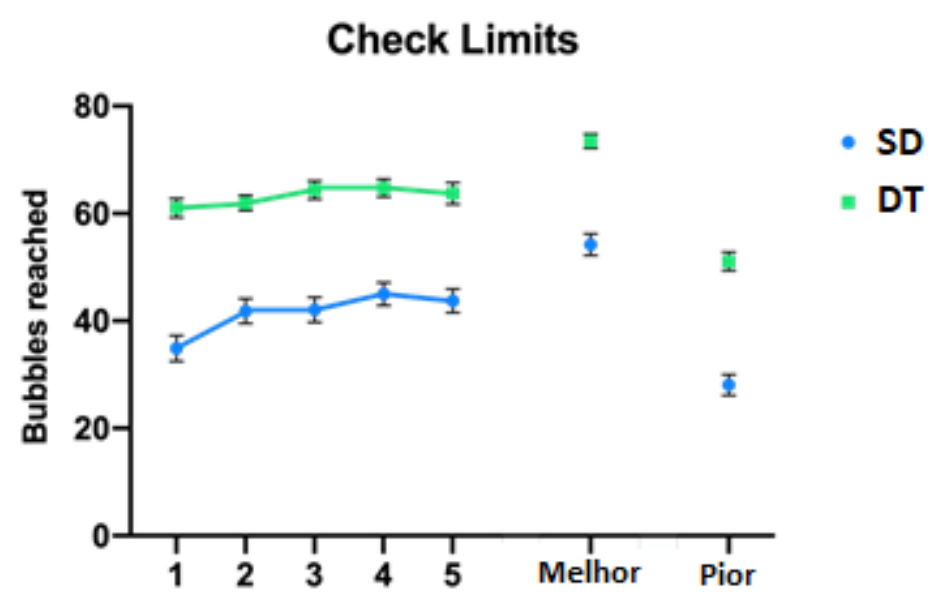

SD: Síndrome de Down; DT: Desenvolvimento Típico. Fonte: Maely Pedrosa Pimentel, 2020.

\subsubsection{Timing Coincidente}

\subsubsection{Aquisicãão}

A MANOVA revelou efeito significativo para o grupo [Wilks' lambda $=0.560, \mathrm{~F}(3$, $\left.117)=30.7, \mathrm{p}<0.001, \eta_{\mathrm{p}}{ }^{2}=0.44\right]$ e blocos [Wilks' lambda $=0.804, \mathrm{~F}(3,117)=9.51, \mathrm{p}<0.001$, $\left.\eta_{\mathrm{p}}{ }^{2}=0,20\right]$. Nenhuma interação entre Grupo e Blocos foi encontrada. Os RM-ANOVAs de acompanhamento separados para os erros de temporização encontraram os seguintes efeitos:

\subsection{Erro constante}

A figura 11 apresenta os EC durante a aquisição para os grupos SD e DT. A ANOVA revelou efeito significativo apenas para o grupo $\left[\mathrm{F}(1,119)=79.5, \mathrm{p}<0.001, \mathrm{y}_{\mathrm{p}}{ }^{2}=0.40\right]$. Este resultado mostrou que o grupo DT teve um maior EC $(377 \pm 70 \mathrm{~ms})$ do que o grupo SD (189 $\pm 68 \mathrm{~ms})$, mostrando que o grupo DT antecipou mais do que o grupo SD. 
Figura 11 - Erro constante (ms) para grupos (DS, TD) e blocos para todas as fases do estudo. Os valores representados como média e erros padrão.

EC

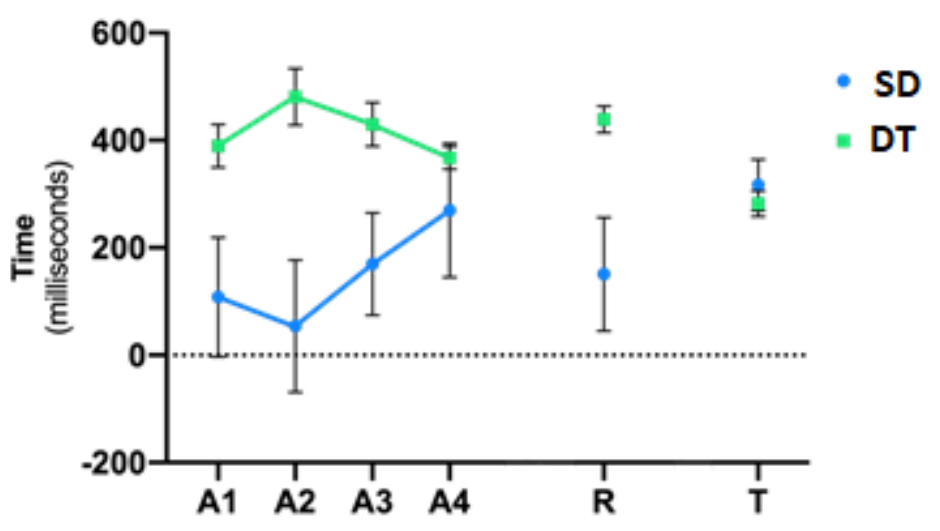

A1 - A4: blocos de aquisição; R: blocos de retenção; T: blocos de transferência; SD: Síndrome de Down; DT: desenvolvimento típico. Fonte: Maely Pedrosa Pimentel, 2020.

\subsection{Erro absoluto}

O padrão de erros absolutos é ilustrado na figura 12. Efeitos significativos foram encontrados para Blocos $\left[\mathrm{F}(1,119)=8.08, \mathrm{p}=0.005, \mathrm{y}_{\mathrm{p}}{ }^{2}=0.06\right]$ e $\operatorname{Grupos}[\mathrm{F}(1,119)=79.4$, $\left.\mathrm{p}<0.001, \mathrm{y}_{\mathrm{p}}^{2}=0.40\right]$. Este resultado sugere melhora de A1 para A4 em ambos os grupos SD (A1: 1184 $\pm 59 \mathrm{~ms} ;$ A4: $982 \pm 63 \mathrm{~ms})$ e DT (A1: 503 $\pm 412 \mathrm{~ms}$; A4: 412 $\pm 64 \mathrm{~ms})$. Além disso, o grupo SD apresentou EA (1083 $\pm 49 \mathrm{~ms})$ muito maior que o grupo DT (458 $\pm 50 \mathrm{~ms})$.

Figura 12 - Erro absoluto (ms) para grupos (DS, TD) e blocos para todas as fases do estudo. Os valores representados como média e erros padrão.

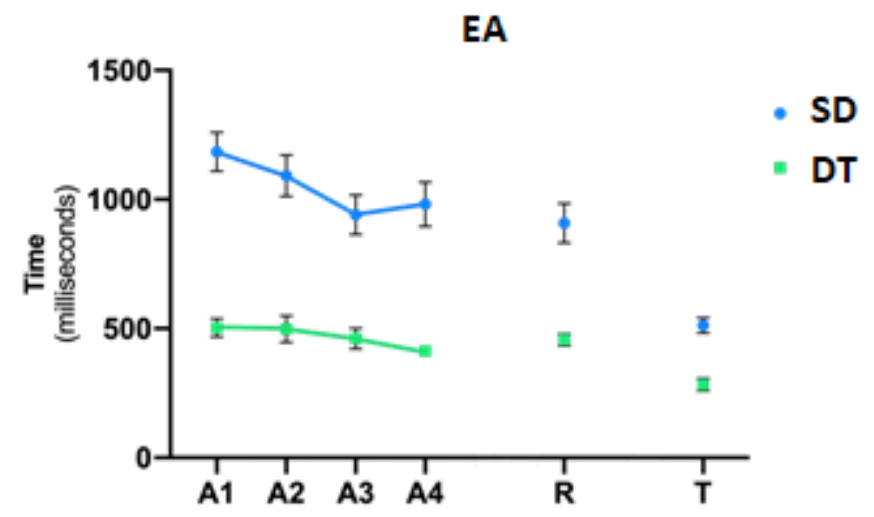

A1 - A4: blocos de aquisição; R: blocos de retenção; T: blocos de transferência; SD: Síndrome de Down; DT: desenvolvimento típico. Fonte: Maely Pedrosa Pimentel, 2020. 


\subsection{Erro variável}

O erro variável durante a aquisição está representado na Figura 13. Houve efeitos significativos para Blocos $\left[\mathrm{F}(1,119)=26.3, \mathrm{p}<0.001, \mathrm{y}_{\mathrm{p}}{ }^{2}=0.18\right]$ e $\operatorname{Grupos}[\mathrm{F}(1,119)=50.9$, $\left.\mathrm{p}<0.001, \mathrm{y}_{\mathrm{p}}^{2}=0,30\right]$. Além disso, foi encontrada uma interação significativa para Blocos por Grupos $\left[\mathrm{F}(1,119)=6.53, \mathrm{p}=0.012, \mathrm{y}_{\mathrm{p}}^{2}=0.05\right]$. O teste post hoc mostrou que a melhora no EV foi significativa apenas no grupo SD de A1 para A4 (994 $\pm 77 \mathrm{~ms}$, respectivamente; $\mathrm{p}<0.001)$ e uma tendência de melhora no grupo DT $(278 \pm 133 \mathrm{~ms}$, respectivamente; $\mathrm{p}=0.074)$.

Figura 13 - Erro variável (ms) para grupos (DS, TD) e blocos para todas as fases do estudo. Os valores representados como média e erros padrão.

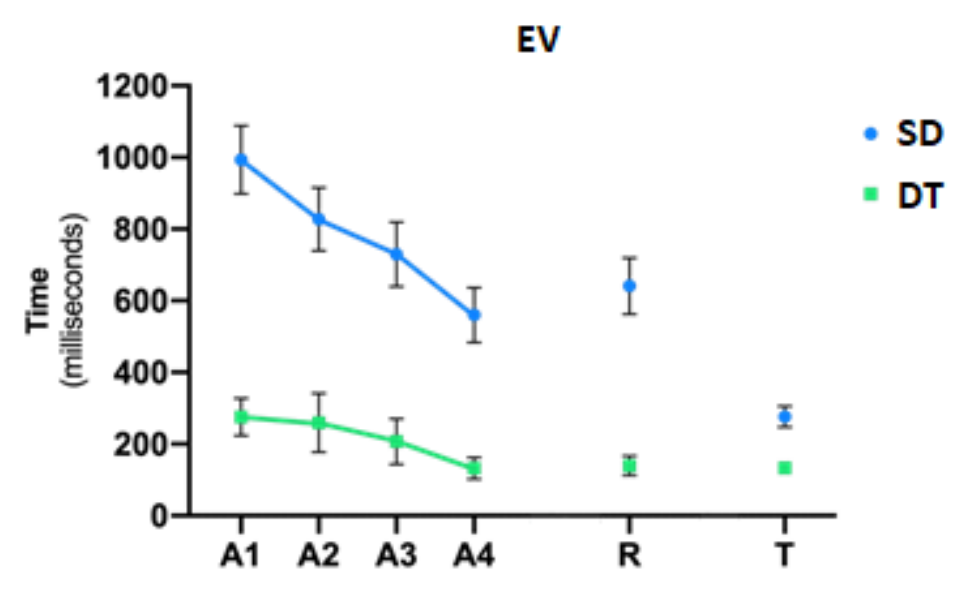

A1 - A4: blocos de aquisição; R: blocos de retenção; T: blocos de transferência; SD: Síndrome de Down TD: desenvolvimento típico. Fonte: Maely Pedrosa Pimentel, 2020.

\subsubsection{Retencão}

A MANOVA revelou efeito significativo para o Grupo [Wilks lambda $=0.655, \mathrm{~F}$ (3, $117)=20.6, \mathrm{p}<0,001, \eta_{\mathrm{p}}{ }^{2}=0.35$ ] e interação para Blocos por Grupo [Wilks 'lambda $=0.903$, $\left.\mathrm{F}(3,117)=9.51, \mathrm{p}=0.007, \eta_{\mathrm{p}}^{2}=0,10\right]$.

RM-ANOVA para acompanhamento separado mostrou interação nos erros de temporização para blocos e grupo $\left[\mathrm{F}(1,119)=4.37, \mathrm{p}=0.039, \mathrm{y}_{\mathrm{p}}{ }^{2}=0.04\right]$ somente para erro constante. O teste post hoc mostrou que o grupo DT apresentou maior EC do que o grupo SD

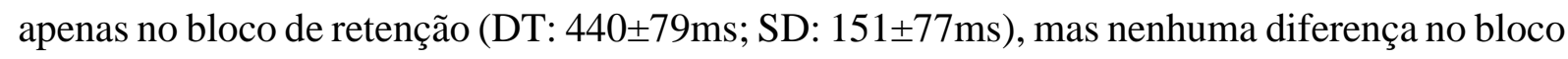

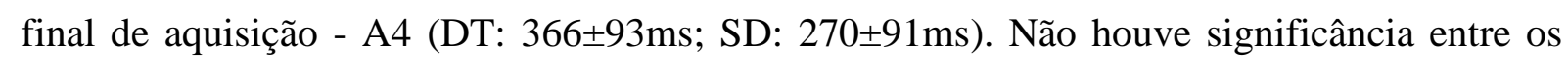


blocos, sugerindo que todos os participantes mantiveram o desempenho adquirido durante a prática.

Quanto aos efeitos para os grupos, os RM-ANOVAs encontraram apenas uma tendência de efeito para o Grupo $\left[\mathrm{F}(1,119)=2.99, \mathrm{p}=0,087, \mathrm{y}_{\mathrm{p}}^{2}=0.02\right]$ para o EC, e efeitos significativos para o EA $\left[\mathrm{F}(1,119)=40.3, \mathrm{p}<0.001, \mathrm{y}_{\mathrm{p}}{ }^{2}=0.25\right.$ e EV $[\mathrm{F}(1,119)=43.9$, p $<0,001, \mathrm{yp} 2=0.27$. Este resultado mostra que, similarmente a fase de aquisição, o grupo SD teve um EA e EV muito maior ( $945 \pm 56 \mathrm{~ms}$ e $600 \pm 49 \mathrm{~ms}$, respectivamente) do que o grupo DT (435 $\pm 58 \mathrm{~ms}$ e $136 \pm 50 \mathrm{~ms}$, respectivamente). As figuras 11, 12 e 13 também apresentam os erros de temporização durante a retenção.

\subsubsection{Transferência}

A MANOVA revelou efeito significativo para grupo [Wilks lambda $=0.641, \mathrm{~F}(3,117)$ $=21,9, \mathrm{p}<0.001, \eta_{\mathrm{p}}{ }^{2}=0.36$ ] e Blocos [Wilks 'lambda $=0.590, \mathrm{~F}(3,117)=27.1, \mathrm{p}<0.001, \eta_{\mathrm{p}}{ }^{2}$ $=0.41$. Também foi encontrada uma interação para Blocos por Grupos [lambda de Wilks = $\left.0.840, \mathrm{~F}(3,117)=7.44, \mathrm{p}<0.001, \eta_{\mathrm{p}}{ }^{2}=0.16\right]$. Os RM-ANOVAs de acompanhamento separados para os erros de temporização encontraram os seguintes efeitos:

\subsection{Erro constante}

Nenhum efeito e interação foram encontrados para EC.

\subsection{Erro absoluto}

Para o EA houve efeito significativo de Bloco $\left[\mathrm{F}(1,119)=51.4, \mathrm{p}<0,001, \eta_{\mathrm{p}}{ }^{2}=0.30\right]$, sugerindo que os padrões de erros absolutos foram diferentes durante a transferência em relação ao A4, porém tanto o grupo SD quanto o DT melhoraram o EA de A4 (SD: 982 $\pm 63 \mathrm{~ms}$; DT: 412 $\pm 64 \mathrm{~ms}$ ) para Transferência-T (SD: 513 $\pm 26 \mathrm{~ms}$; DT: $284 \pm 27 \mathrm{~ms}$ ). Além disso, o efeito para os Grupos $\left[\mathrm{F}(1,119)=53.0, \mathrm{p}<0,001, \eta_{\mathrm{p}}{ }^{2}=0.20\right]$ mostrou que o grupo SD teve maior EA

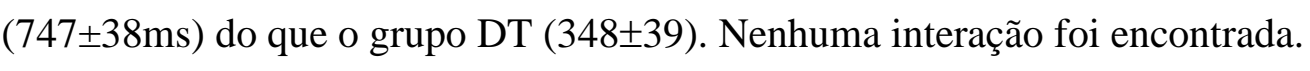




\subsection{Erro variável}

Para o erro variável, efeitos significativos de bloco, $\left[\mathrm{F}(1,119)=14.8, \mathrm{p}<0,001, \eta_{\mathrm{p}}{ }^{2}=\right.$ 0.11] e Grupo $\left[F(1,119)=30.5, p<0,001, \eta_{p}{ }^{2}=0.20\right]$ foram encontrado e uma interação significativa entre Bloco e Grupo $\left[\mathrm{F}(1,119)=14.9, \mathrm{p}<0.001, \eta_{\mathrm{p}}{ }^{2}=0.11\right]$ (ver Figura 13). O teste post hoc mostrou que o erro variável foi menor no bloco de transferência $\mathrm{T}$ do que durante

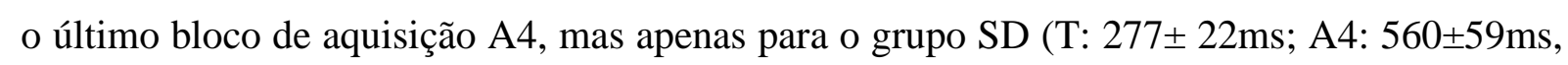
$\mathrm{p}<0.001)$.

\subsubsection{Tempo de Reação Total Simples}

Encontramos diferenças significativas entre Blocos para ambos os grupos SD (bloco 1: 2333 $\pm 1267 \mathrm{~ms}$; bloco 2: 1741 $\pm 1279 \mathrm{~ms} ; \mathrm{p}<0.001$ ) e DT (bloco 1: 449 $\pm 208 \mathrm{~ms}$; bloco 2: 405 $\pm 136 \mathrm{~ms} ; \mathrm{p}=0.050$ ). Além disso, houve diferenças entre os grupos no bloco 1 (SD:

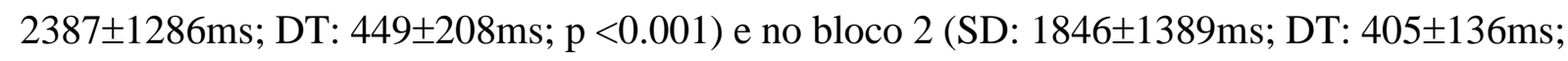
$\mathrm{p}<0.001$ ) (Figura 16).

Figure 14 - Desempenho na tarefa Tempo de Reação do grupo SD e DT, no bloco 1 (média de 7 primeiras tentativas) e no bloco 2 (média de 7 últimas tentativas).

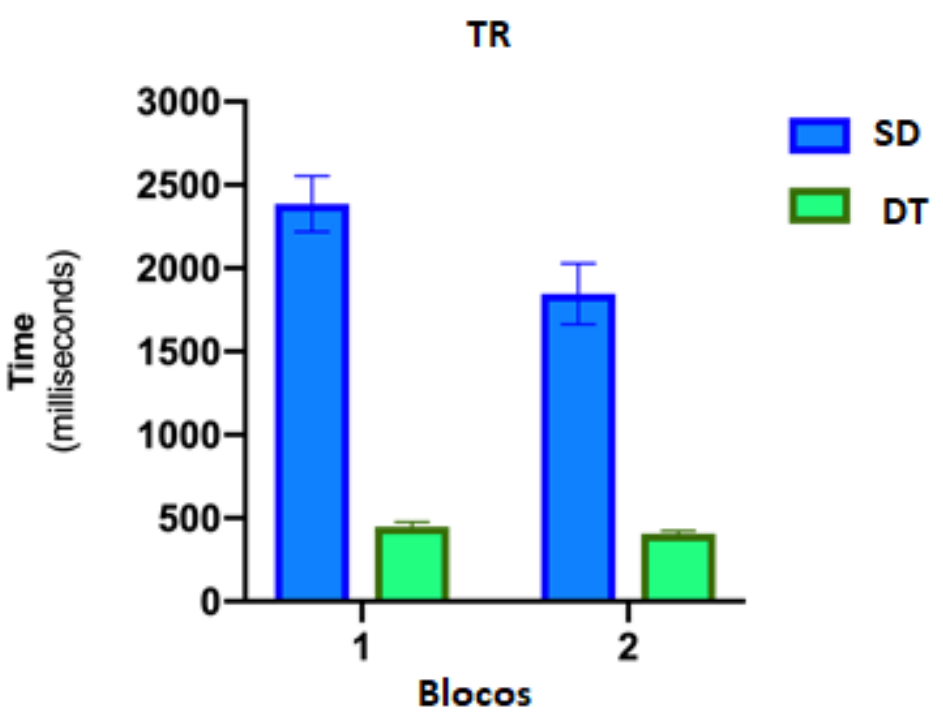

SD: Síndrome de Down; DT: Desenvolvimento Típico. Fonte: Maely Pedrosa Pimentel, 2020. 


\section{DISCUSSÃO}

O principal objetivo deste estudo foi investigar se pessoas com Síndrome de Down são capazes de melhorar o desempenho motor em tarefas virtuais, para isso utilizamos três softwares: Check Limits, Timing Coincidente e Tempo de Reação Total (TRT). Estas tarefas foram aplicadas com base em um protocolo de curto prazo, assim como realizado por DE MELLO MONTEIRO et al. (2017) que afirmam que um protocolo transversal (um dia) para tarefas simples é suficiente para observar os resultados desejados, no entanto reforçam a necessidade de um acompanhamento longitudinal.

Nossa hipótese inicial de melhora do desempenho com a prática em tarefa virtual, tanto no grupo de SD quanto no grupo de DT foi parcialmente confirmado. Isto demonstra que em decorrência da prática foi alcançado melhor desempenho da tarefa, por consequente melhoria da qualidade, organização e tempo dos movimentos.

No jogo Check Limits foi constatado que houve aumento na quantidade de bolhas alcançadas da primeira tentativa para a quarta tentativa apenas para o grupo SD, isso significa melhora do desempenho durante a prática pois a sequência de movimentos passa a ser mais fluente e harmonica. O grupo DT não apresentou melhora significativa e isso pode ser explicado por DE MELLO MONTEIRO et al. (2017) que discute o fator motivação durante a execução da tarefa, pois os indivíduos com DT parecem considerar a tarefa fácil e isso pode afetar o processo de aprendizagem motora, visto que o individuo presta menos atenção e reduz o envolvimento e participação. Logo, por mais que o grupo DT tenha alcançado o maior números de bolas que o Grupo SD, devido a capacidade de controlar melhor os movimentos e processamento mais rápido de informações, não apresentou melhora significativa da primeira tentativa para a quarta tentativa.

Não houve melhora da primeira tentativa para a quinta tentativa em ambos os grupos, este resultado pode estar associado ao maior esforço para equilibra-se e manter a força necessária para realizar a tarefa por um tempo maior (PAUL et al, 2019), pois para a execução do Check Limits o participante precisa ficar em pé e alcançar o maior número de bolhas possíveis com os membros superiores, então a perda de desempenho na quinta tentativa pode ter sido influenciada pela dificuldade em manter a postura ortostatica por maior tempo associado a movimentação dos braços para completar a etapa do jogo.

Considerando os resultados do Timing Coincidente na fase de aquisição foi revelado que o grupo DT teve maior EC que o grupo $\mathrm{SD}$, mostrando que o grupo DT apresentou maior antecipação. Segundo LATASH, 2007 a antecipação do movimento ocorre pois os indivíduos 
típicos se concentram na probabilidade de ocorrência entre as opções e as pessoas com SD não utilizam esta informação de probabilidade, além de apresentarem lentidão, seleção de estratégias incomuns e atraso na aquisição dos principais padrões de movimentos para execução de tarefas manuais. Outra especulação é que estes indivíduos realizam movimentos mais lentos na tentativa e obter mais precisão, essa estratégia é adotada para conseguir melhor controle motor, logo é considerada uma reação adaptativa, porém podem melhorar seu desempenho, de forma intencional, com a treino (TORRIANI-PASIN et al, 2013).

O grupo SD apresentou EA muito maior que o grupo DT, ou seja, apresentaram maior dificuldade para realizar a coincidência pois não conseguem sincronizar o tempo com eficiência. O cerebelo é responsável por coordenar a atividade que necessita de uma ocorrência precisa de tempo, além de programar o timing também lhe é atribuído a função de planejar, e realizar padrões de atividade dos músculos durante o movimento (HANAKAWA, DIMYAN e HALLETT, 2008). Assim, indivíduos com disfunções cerebrais podem apresentar dificuldade para realizar atividades que demandam maior acurácia, evidenciando ainda mais seu papel no planejamento e regulação do movimento (TORRIANI-PASIN et al, 2013). Ainda em relação ao erro absoluto foi encontrado melhora do bloco A1 para A4 para ambos os grupos, essa melhora do grupo SD pode ser explicada por BERG et al. (2012) que sugere que a prática resulta em aquisição e domínio de habilidades baseados em conceitos de plasticidade neural e nos princípios da aprendizagem motora. Sendo que a plasticidade neural permite o crescimento e reorganização contínua do sistema nervoso como um produto da prática, experiência e interação com estímulos ambientais.

O grupo SD, durante a aquisição, apresentou maior EV que o Grupo DT, ou seja, apresentou maior variabilidade, independente da proximidade de cada tentativa com alvo, levando em consideração a precisão (MORAES et al, 2019). Os indivíduos com Síndrome de Down tendem a realizar tarefas de coincidência de forma mais instável e irregular quando comparados aos sujeitos do grupo controle, devido alterações no sistema viso-motor e déficit das habilidades motoras perceptivas (GIMENEZ, STEFANONI, FARIAS, 2007). No entanto, o grupo SD mostrou melhora do EV de A1 para A4, pois julga-se que o treino favoreceu a execução de ações programadas resultando em eficiência no desempenho.

Na retenção foi observado que o grupo de DT apresentou maior EC que o grupo SD e diferença significativa quando comparado o resultado do bloco A4 com o Bloco R, porém isso não ocorreu com o grupo SD, em todos dos outros erros de temporização não houve diferença significativa entre estes blocos, sugerindo que todos os participantes mantiveram o desempenho adquirido durante a prática. É importante ressaltar que, mesmo considerando pouco o número 
de repetições, foi suficiente para manter o desempenho, como observados nos gráficos, principalmente em relação ao EA e EV, onde na fase inicial os participantes apresentaram maior quantidade de erros e alta demanda de atenção e posteriormente redução dos erros e provável redução da demanda de atenção como corroborado por DE MELLO MONTEIRO et al, (2017).

Em relação ao bloco de transferência, tanto o grupo SD quanto o grupo DT melhoraram o EA quando comparado com bloco A4 da aquisição, o EV também foi menor no bloco T, mas somente para o grupo SD, ou seja, uma situação com aumento da velocidade da tarefa não causou queda significativa do desempenho e mais uma vez os participantes com SD que começaram com baixo desempenho, após a prática mostrou boa capacidade de adaptação diante de uma nova situação. A melhora do desempenho com aumento da velocidade também foi verificada por QUADRADO et al. (2017) quando descreveu sobre o erro absoluto corroborando com os achados que tarefas com velocidade aumentada reduzem a variabilidade das respostas, proporcionando melhor desempenho. Os indivíduos com SD conseguiram se organizar, ajustando os movimentos para alcançar a precisão exigida pela tarefa. Quando confrontados com mudanças inesperadas, geralmente são adeptos a ajustar seu trajeto de movimento para acomodar novas restrições do ambiente (BERG et al, 2012). O objetivo principal da prática não é apenas para facilitar a realização de efeitos temporários durante a aquisição, é também fornecer maior duração do desempenho (atribuído à aprendizagem) nos testes de retenção e transferência.

No software TRT_S houve diferença significativa entre o bloco 1 do grupo SD e DT e também no bloco 2 quando é feita a mesma comparação. Isso pode ser explicado por GIMENEZ, STEFANONI e FARIAS (2007) que relatam que o tempo de reação nos indivíduos portadores de Síndrome de Down é maior quando comparados com individuos normais, esta limitação está associadas às condições estruturais do organismo relacionadas a lentidão em seu processamento, incapacidade de formar e utilizar programas percepto motores necessários para gerar uma resposta mais rápida. Também foi observado que ocorreu melhora significativa do tempo de reação total do bloco 1 para o bloco 2 no grupo SD e no Grupo DT. Esse resultado pode ser justificado por ALEIXO, TEIXEIRA e VIEIRA, 2012, que citam a redução significativa do tempo de reação total como consequencia da prática e pode se interpretado como efeito de aprendizado.

Muitos autores citam o uso da RV para reabilitação de pessoas com SD. RHAMAN e RHAMAN, (2010) pontuou a importância da inclusão de sistemas de jogos de RV na prática de neuro-reabilitação nas atividades e ocupações cotidianas, pois os usuários interagem com 
uma variedade de imagens exibidas de forma significativa e motivadora, podem ser adaptados, graduados e executados e várias formas para facilitar o processo de aprendizagem. 


\section{LIMITAÇÕES}

Como limitações deste trabalho, podemos citar (1) o protocolo foi transversal, provavelmente uma intervenção longitudinal poderia oferecer dados mais fidedignos; (2) não paridade entre sexos. 


\section{CONCLUSÃO}

Com base nos resultados encontrados, os participantes com Síndrome de Down melhoraram seu desempenho durante a prática em tarefas virtuais, desta forma, estes jogos podem contribuir para aprendizagem motora destes indivíduos. No jogo CheckLimits houve aumento das bolas alcançadas apenas no grupo SD, no Timing Coincidente os indivíduos com SD conseguiram melhorar o desempenho na fase de aquisição com redução do erro absoluto em ambos os grupo e redução do erro variável apenas no grupo SD, conseguiram manter o desempenho adquirido durante a prática e transferir o desempenho para a tarefa com maior velocidade, no TRT houve melhora significativa em ambos os grupos, com redução do tempo de reação.

Embora indivíduos com SD apresentem alterações nos padrões e estratégias de movimentos e nas habilidades percepto-motoras, a atividade de prática virtual pode ser uma forma diferenciada para propiciar participação funcional devido capacidade de melhora no desempenho nestas tarefas, logo, seu uso pode ser incentivado, sendo utilizado como mais um recurso para programas de reabilitação motora. 


\section{REFERÊNCIAS ${ }^{1}$}

ADAMOVICH, Sergei. V. et al., Sensorimotor training in virtual reality: a review. NeuroRehabilitation, v.25, p.29-44, 2009.

ALEIXO, Ivana Montandon Soares; TEIXEIRA, Francisco Azra Cardoso Malab; VIEIRA, Márcio Mário. Relação entre tempo de reação e tempo de movimento em uma habilidade motora com crianças. Motricidade, v. 8, n. 2, p. 1032-1037, 2012.

ALEXANDER, Myriam. et al. Morbidity and medication in a large population of individuals with Down syndrome compared to the general population. Developmental Medicine \& Child Neurology, v. 58, n. 3, p. 246-254, jul, 2016.

ANTONARAKIS, Stylianos. E. et al. Down syndrome. Nature Reviews Disease Primers, v. 6, n. 1, p. 1-20, 2020.

ASSIS, Caroline Shihara. et al. Functional independence measure in patients with intermittent claudication. Journal of school of nursing university of São Paulo, v. 49, n. 5, p. 756-761, may, 2015.

BERG, Patti et al. Motor Control Outcomes Following Nitendo Wii Use by a Child With Down Syndrome. Pediatric Physical Therapy, p. 78-84, 2012.

BERNARDONI, Fabio. et al. Virtual Reality Environments and Haptic Strategies to Enhance Implicit Learning and Motivation in Robot-Assisted Training. In: 2019 IEEE 16th International Conference on Rehabilitation Robotics (ICORR). IEEE, p. 760-765, 2019.

BHATTACHARYYA, Ranjan; SANYAL, Debasish; BHATTACHARYYA, Subita. Diagnostic algorithm of Down syndrome by minor physical anomaly. Indian journal of psychiatry, v. 60, n. 4, p. 398, jun, 2018.

BURDEA, Grigore. Virtual Rehabilitation - Benefits and Challenges. Review Papper: Based on the Key note address with the same title given at the 1 st International Workshop on Virtual Rehabilitation, Lausanne, Switzerland, November 7-7, 2002. Yearbook of Medical Informatics 2003.

CHIVIACOWSKY, Suzete et al. Self-controlled feedback enhances learning in adults with Down Syndrome. Revista Brasileira de Fisioterapia, v. 16, n. 3, 191-196, jun, 2012.

CARDOSO, Aline Christine das Neves Cardoso et al. Motor performance of children with Down syndrome and typical development at 2 to 4 and 26 months. Pediatric physical therapy, v. 27, n. 2, p. 135-141, 2015.

CORNEJO, Jadisha Yarif Ramírez et al. Down syndrome detection based on facial features using a geometric descriptor. Journal of Medical Imaging, v. 4, n. 4, p. 044008, nov, 2017.

${ }^{1}$ De acordo com a Associação Brasileira de Normas Técnicas. NBR 6023 (2020). 
CROCETTA, Tânia Brusque et al. Virtual reality software package for implementing motor learning and rehabilitation experiments. Virtual Reality, v. 22, n. 3, p. 199-209, 2018.

CROCETTA, Tânia Brusque et al. Investigando a correlação entre a fadiga mental e o tempo de reação total: Estudo Piloto. Revista Brasileira de Prescrição e Fisiologia do Exercício, v. 11, n. 65, p. 143-155, aug, 2017.

ECKNER James T et al. A novel clinical Test of Recognition Reactian Time in Healthy Adults. Psychological Assessment, V. 24, n. 1, p. 249-254, mar, 2012.

DE MELLO MONTEIRO, C. B. et al. Short-term motor learning through non-immersive virtual reality task in individuals with down syndrome. BioMed Central Neurology, v. 17, n. $1,2017$.

FERREIRA, Vinicius H; WAGNER Paulo R. A Tecnologia na Escola: Analisando o Perfil Tecnológico do Aluno de Ensino Médio. Anais do $\mathbf{2 3}^{\mathbf{0}}$ Simpósio de Informática na Educação, Rio de Janeiro, 26-39 nov., 2012.

FORNER-CORDERO, Arturo. et al. Improved Learning a Coincident Timing Task With a Predictable Resisting Force. Motor Control. v. 11, p. 1-17, mar, 2017.

GENSOUS, Noémie et al. Down Syndrome, Ageing and Epigenetics. In: Biochemistry and Cell Biology of Ageing: Part II Clinical Science. Springer, Singapor, p. 161-193, 2019.

GIMENEZ, Roberto; STEFANONI Fernanda Fuin; FARIAS Patrícia Buttaro: Relation between temporal synchronization ability and fundamental movement patterns striking and catching in individuals with and without Down syndrome. Rev Bras Ciên. Mov, v. 15, n. 3, p. 95-101, 2007.

HANAKAWA, Takashi; DIMYAN, Michael A; HALLETT. Motor Planning, Imagery, and execution in the Distributed Motor Network: A Timecouse Study with Functional MRI. Cerebral Coxtex, v 18, p. 2775-2788, dec, 2008.

HECK, Vanessa Stumpf et al. Validação dos subtestes verbais da versão de adaptação da Wasi. Avaliação Psicológica, v. 8, n. 1, p. 33-42, abr, 2009.

HOLMEFUR, Marie et al. Longitudinal development of function in children with unilateral cerebral palsy. Developmental Medicine \& child neurology. V. 52, p. 352-357, jul, 2010.

HUGHES-MCCORMACK, Laura Anne et al. Birth incidence, deaths and hospitalisations of children and young people with Down syndrome, 1990-2015: birth cohort study. BMJ open, v. 10, n. 4, p. e033770, mar, 2020.

JUNIOR, Renato Sobral Monteiro; SILVA Elirez Bezerra. Effectiveness of the virtual rehabilitation on body balance and motor abilities of Individuals with neuromotor Impairment: a systematic review. Brazilian Journal of physical activity and health, v. 17, n. 3, p. 224230, mar, 2012.

LATASH, Mark L. learning motor synergies by persons with Down Syndrome. Journal of Intellectual Disability Research, v. 51, n. 12, p. 962-971, dec, 2007. 
MACKENZIE, Samuel J. et al. Using Grasping Tasks to Evaluate Hand Force Coordination in Children With Hemiplegic Cerebral Palsy.Archives of Physical Medicine and rehabilitation, v. 90, p. 1439-1442, aug, 2009.

MALHEIROS, Silvia Regina Pinheiro el al. Computer task performance by subjects with Duchenne muscular dystrophy. Neuropsychiatric Disease and Treatment. 12:41-48, dec, 2016.

MANSUR, Samira Schultz; MARCON Adair José. Perfil motor de crianças e adolescentes com deficiência mental moderada. Revista Brasileira de Crescimento e Desenvolvimento Humano. v16, n 3, p. 09-15, 2006

MENDES, Felipe Augusto dos Santos et al. Motor learning, retention and transfer after virtualreality-based training in Parkinson's disease - effect of motor and cognitive demands of games: a longitudinal, controlled clinical study. Physiotherapy, v. 98, p. 217-223, sep, 2012.

MENEZES, Lilian Del Ciello et al., Motor learning in mobile (cell phone) device in Down syndrme patients - pilot Project. MedicalExpress, v. 2, n. 4, aug, 2015.

MORAES, Íbis Ariana Peña et al. Motor learning and transfer between real and virtual environments in young people with autism spectrum disorder: A prospective randomized cross over controlled trial. Autism Research, v. 13, n. 2, p. 307-319, 2020.

MORRIS, Joan K. et al. Cytogenetic and epidemiological findings in Down syndrome: England and Wales 1989-2009. American journal of medical genetics Part A, v. 158, n. 5, p. 11511157, mar, 2012.

NOFFS, Maria Helena da Silva et al. Desempenho cognitivo de pacientes com epilepsia do lobo temporal e epilepsia mioclônica juvenil: avaliação por meio da Escala WAIS-III. Journal of epilepsy and clinical neurophysiology, v. 12, n. 1, p. 7-12, 2006.

PAUL, Yvonne et al. The health benefits of exercise therapy for patients with down syndrome: A systematic review. African journal of Disability, v. 8, oct, 2019.

PEREIRA, Karina et al. Infants with Down syndrome: percentage and age for acquisition of gross motor skills. Research in developmental disabilities, v. 34, n. 3, p. 894-901, mar, 2013.

POSSEBOM, Weliton Folli et al. Aprendizagem motora em pessoas com síndrome de down: tarefa de labirinto no computador. Temas sobre desenvolvimento, v. 19, n. 104, p. 54-60, 2013.

PRESSON, Angela P. et al. Current estimate of Down syndrome population prevalence in the United States. The Journal of pediatrics, v. 163, n. 4, p. 1163-1168, oct, 2013.

QUADRADO, Virgínia Helena et al. Motor Learning from virtual reality to natural environments in individuals with Duchenne muscular dystrophy. Disability and Rehabilitation: Assistive Technology, v. 14, p. 12-20, nov, 2017. 
RAFII, Michael S. et al. Down syndrome. In: Handbook of clinical neurology. Elsevier, p. 321-336, 2019.

RAND, Debbie; KIZONY R; WEISS Patrice Lynne Virtual reality rehabilitation for all: Vivid GX versus Sony PlayStation II Eye Toy. Proc. 5th Intl Conf. Disability, Virtual Reality \& Assoc. Tech., Oxford, UK, 2004.

RAHMAN, Samia Abdel; RAHMAN, A. Efficacy of virtual reality-based therapy on balance in children with Down syndrome. World Applied Sciences Journal, v. 10, n. 3, p. 254-261, 2010 .

RIBEIRO, Marcelo. et al. Validação da Versão Brasileira da Medida de Independência Funcional. ACTA Fisiatr, v. 11, n. 2, p. 72-76, 2004.

SANCHEZ, Yerly; PINZON, David; ZHENG, Bin. Reaction time for processing visual stimulus in a computer-assisted rehabilitation environment. Disability and Rehabilitation: Assistive Technology, v. 12, n. 7, p. 725-729, dec, 2017.

SILVA, Talita Dias et al. Aprendizagem motora em tarefa virtual na paralisia cerebral. Tema sobre Desenvolvimento, v. 19, n. 104, jan, 2013.

SILVA-FILHO, Edsin et al. Neuromodulation treats Chikungunya arthralgia: a randomized controlled trial. Sci Rep. v. 8, n. 1, p. 16010, Oct 2018.

SVEISTRUP, Heidi. Motor rehabilitation using virtual reality. Journal of NeuroEngineering and Rehabilitation, v. 1 n. 1, dec, 2004.

TIERI, Gaetano et al. Virtual reality in cognitive and motor rehabilitation: facts, fiction and fallacies. Journal Expert Review of medical Devices, V. 15, jan, 2018

TORRIANI-PASIN, Camila et al. Performance of Down syndrome subjects during a coincidente timing task. International Archives of Medicine, v. 6, n. 1, p. 15, apr, 2013.

TRIGUEIRO, Larissa Coutinho de Lucena et al. Perfil sociodemográfico e índice de qualidade de vida de cuidaddores de pessoas com deficiência física. Fisioterapia e Pesquisa, v. 18, p. 223-227, sep, 2011.

YATES, Denise Balem et al. Apresentação da Escala de Inteligência Wechsler Abreviada (WASI). Avaliação Psicológica, v. 5, n. 2, p. 227-233, dez, 2006.

ZAGO, Matteo et al. Gait and postural control patterns and rehabilitation in Down syndrome: a systematic review. Journal of physical therapy science, v. 32, n. 4, p. 303-314, apr, 2020.

ZWIERKO, Teresa et al. Speed of Visual Sensoriomotor Processes and Conductivity of Visual Pathway in Volleyball Players. Journal of Human Kinetics, v. 23, p. 21-27, mar, 2010.

WILL, Elizabeth A. et al. Sensory processing and maladaptive behavior: Profiles within the Down Syndrome phenotype. Physical \& occupational therapy in pediatrics, v. 39, n. 5, p. 461-476, may, 2019. 


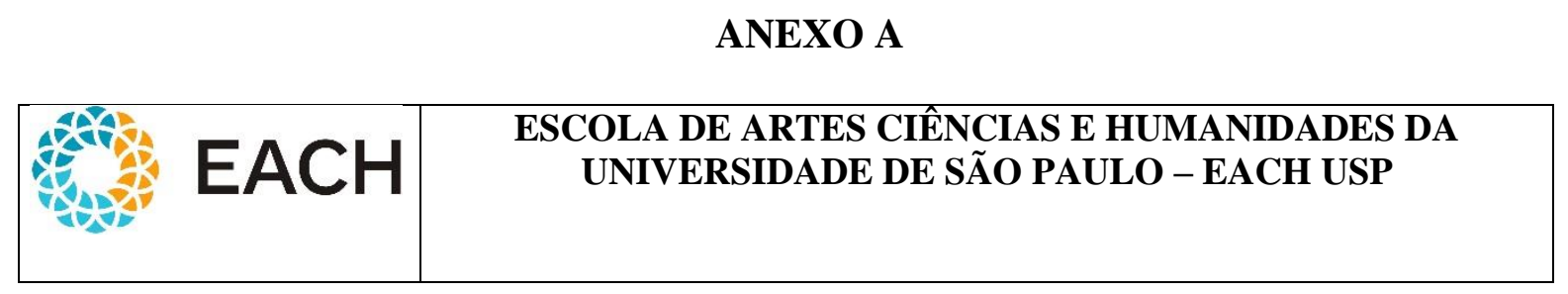

TERMO DE CONSENTIMENTO LIVRE E ESCLARECIDO

\section{Título do Projeto: ANÁLISE DO DESEMPENHO DE TAREFA VIRTUAL EM PESSOAS COM SÍNDROME DE DOWN}

Prezado (a) Senhor (a), o (a) menor pelo (a) qual o (a)

Senhor (a) é responsável, está sendo convidado (a) a participar de uma pesquisa que visa verificar se uma tarefa motora realizada por meio de interfaces virtuais possibilita maior desempenho em indivíduos com Síndrome de Down. Os resultados serão importantes para verificar a aplicabilidade da realidade virtual, nos indivíduos com Síndrome de Dow.

O jogo MoveHero apresenta esferas que caem, em quatro colunas imaginárias na tela do computador, no ritmo de uma música, a tarefa consiste em não deixar essas esferas caírem. O jogo capta os movimentos do participante por meio de uma webcam, a uma distância predeterminada da tela do computador. Portanto, o jogo exige que o participante tenha uma estratégia de antecipar o movimento para alcançar as esferas dentro desses círculos e transformam em dados importantes, como os acertos, esferas perdidas, antecipação, média de tempo, maior e menor tempo e salva estes dados para análises futuras.

A sua participação irá ajudar com informações que nos permitirão identificar se jogos com realidade virtual propiciam aprendizagem motora em pessoas com Síndrome Down e estes resultados podem ser importantes para oferecer aos profissionais de reabilitação maior conhecimento sobre a utilização da realidade virtual como recurso terapêutico e contribuir no processo de reabilitação deste público.

As medidas serão analisadas na Escola de Artes, Ciências e Humanidades da Universidade de São Paulo - EACH - USP. Os dados obtidos nesta pesquisa serão publicados no meio acadêmico e científico e os jogos estarão disponíveis para novas pesquisas e para intervenções de profissionais da saúde na reabilitação de seus pacientes.

A coleta das informações será feita por meio da utilização do jogo executado em computador com dispositivos para registro do movimento executado pelo participante. $\mathrm{O}$ uso do computador e seus acessórios não requer nenhum conhecimento prévio e o jogo proposto é 
divertido e desafiador. O jogo será realizado uma vez por semana por um período de 15 semanas seguidas, cada sessão pode demorar aproximadamente 30 minutos.

Ele (a) não precisa responder a todas as perguntas e nem realizar algum jogo, caso não queira. A participação dele (a) na pesquisa é voluntária.

Os riscos destes procedimentos são mínimos, pois envolvem medições não-invasivas. A execução será em ambiente reservado, com a presença apenas dos pesquisadores e profissionais qualificados para ajudar durante sua execução. Se ele (a) sentir qualquer desconforto pode pedir para parar e será auxiliado pelos profissionais responsáveis.

Os dados serão tratados com total sigilo. Sua identidade será preservada, pois cada indivíduo será identificado por um número. O que nos importa são as respostas dos participantes, e não quem as forneceu.

Ele (a) poderá se retirar da pesquisa a qualquer momento, basta informar aos pesquisadores.

Solicitamos sua autorização para o uso dos dados para a produção de artigos técnicos e científicos. Solicitamos também sua autorização para utilizarmos uma filmadora durante a execução do jogo. Sua privacidade será mantida através da não-identificação do nome do participante. As imagens servirão apenas para divulgação do projeto e todos os cuidados para não identificação do participante será prioridade.

Agradecemos sua compreensão e colaboração.

Mestranda Maely Pedrosa Pimentel

Fone: (27) $99998-0280$

E-mail: maelypedrosa@usp.br

Endereço: Escola de Artes, Ciências e Humanidades

Universidade de São Paulo

Av. Arlindo Béttio, 1000 Ermelino Matarazzo

São Paulo - SP CEP: 03828-000

Informações: (11) 2648-0067

Eu,

identificação número portador do documento de responsável legal de ,e tendo sido ele (a) convidado (a) a participar como

voluntário (a) da pesquisa ANÁLISE DO DESEMPENHO DE TAREFA VIRTUAL EM PESSOAS COM SÍNDROME DE DOWN, recebi da fisioterapeuta Maely Pedrosa Pimentel, discente mestranda da Universidade de São Paulo, responsável por sua execução, as seguintes informações que me fizeram entender sem dificuldades e sem dúvidas os seguintes aspectos: 
Que a importância desta pesquisa é que ela estará colaborando no teste de jogos sérios com uso de recursos de realidade virtual em computador. Estes jogos poderão permitir que um indivíduo com dificuldade na aprendizagem motora possa ter as oportunidades necessárias à aquisição ou desenvolvimento de funções motoras durante sua reabilitação de forma mais agradável e motivadora.

Que os resultados que se desejam alcançar são os seguintes: O uso repetido dos jogos sérios com realidade virtual pode influenciar o desempenho em atividades da vida diária, pois se espera que eles possam ser influenciados pelas experiências vividas nos movimentos propostos pelos jogos, considerando as restrições físicas e ambientais.

Que esta pesquisa começará em julho de 2018 e terminará em Dezembro de 2018.

Que a pesquisa será feita da seguinte maneira: os jogos serão praticados em ambiente reservado, preferencialmente com a presença de apenas um pesquisador. O (A) menor será acomodado (a) confortavelmente a uma distância predeterminada do computador. A tarefa do jogo será demonstrada verbalmente pelo pesquisador e haverá um número fixo de tentativas para que ele (a) se familiarize com o jogo e com o movimento do jogo e suas regras. Sei que o jogo será realizado uma vez por semana por um período de 15 semanas seguidas e que tempo para completar o jogo não será menor que 15 minutos e não mais do que 35 minutos.

Que ele (a) poderá participar de mais de uma etapa, podendo ser convidado (a) a jogar mais de uma vez ou então em mais de um tipo de jogo.

Que os incômodos que poderá sentir são os seguintes: Ficar cansado (a), ficar enjoado (a), sentir dor, não conseguir executar o movimento necessário para que o jogo seja realizado. Se ele (a) sentir qualquer tipo de desconforto, sei que poderá avisar o pesquisador e parar imediatamente de realizar os jogos, sem qualquer prejuízo.

Que os possíveis riscos à saúde física e mental são: Haver algum desequilíbrio durante a execução dos movimentos para participar dos jogos virtuais, sentir dor ao executar um movimento, ficar enjoado (a) ou cansado (a). Também pode se sentir constrangido (a) com a realização dos movimentos ou não entender o que precisa ser executado. Mas também sei que ele (a) pode pedir para parar a qualquer momento, bastando avisar o pesquisador da sua vontade.

Que deverei contar com a seguinte assistência de Fisioterapeutas. Pesquisadores ligados à Universidade de São Paulo (USP), no endereço:

Escola de Artes, Ciências e Humanidades

Universidade de São Paulo

Av. Arlindo Béttio, 1000 Ermelino Matarazzo

São Paulo - SP CEP: 03828-000

Informações: (11) 2648-0067

Sendo responsáveis por ela: 
a) Prof. Dr. Fernando Henrique Magalhães

Telefone: + 55 (11) 98322-1272

E-mail: fhmagalhaess@gmail.com

b) Mestranda da Universidade de São Paulo

Maely Pedrosa Pimentel

Telefone: + 55 (27) 9 9998-0280

E-mail: maelypedrosa@usp.br

Que os benefícios que poderei esperar com a participação, mesmo que não diretamente são: Impulsionar e melhorar a capacidade de aprendizagem das habilidades motora de pessoas com Síndrome de Down com a utilização de jogos de realidade virtual. Melhorias nas plataformas tecnológicas, com possibilidade de contribuição para o futuro da reabilitação.

Que a participação dele (a) será acompanhada por pelo menos um pesquisador, devidamente treinado e qualificado para acompanhar a participação, principalmente por Fisioterapeutas Mestrandos da USP.

Que, sempre que eu ou ele (a) desejarmos, serão fornecidos esclarecimentos sobre cada uma das etapas da pesquisa e a qualquer momento.

Que, a qualquer momento, ele (a) poderá se recusar a continuar participando da pesquisa e, também, que eu poderei retirar este meu consentimento, sem que isso nos traga qualquer penalidade ou prejuízo.

Que as informações conseguidas através da minha participação e do (a) menor sob minha responsabilidade não permitirão a identificação da nossa pessoa, exceto aos responsáveis pela pesquisa, e que a divulgação das mencionadas informações só será feita entre os profissionais estudiosos do assunto.

Que as imagens gravadas da participação não permitirão a identificação do (a) menor, exceto aos responsáveis pela pesquisa, e que a divulgação das mencionadas imagens só será feita, quando necessário, para fins de divulgação científica do projeto, sempre sem a identificação do (a) menor.

Que esta pesquisa não acarretará nenhuma despesa para nossa participação.

Que seremos indenizados por qualquer dano que venhamos a sofrer com a participação na pesquisa, podendo ser encaminhado para a Escola de Artes, Ciências e Humanidades Universidade de São Paulo.

Que eu receberei uma via do Termo de Consentimento Livre e Esclarecido. 
Em caso de dúvidas você pode entrar em contato com:

a) Prof. Dr. Fernando Henrique Magalhães

Telefone: + 55 (11) 98322-1272

E-mail: fhmagalhaess@gmail.com

b) Mestrada da Universidade de São Paulo

Maely Pedrosa Pimentel

Telefone: + 55 (27) 99998-0280

E-mail: maelypedrosa@usp.br

Para contato em caso de intercorrências clínicas e reações adversas ou para esclarecimento de dúvidas ou SE VOCÊ TIVER DÚVIDAS E/OU PERGUNTAS SOBRE SEUS DIREITOS COMO PARTICIPANTE DESTA PESQUISA E/OU INSATISFEITO COM A MANEIRA COMO A PESQUISA ESTÁ SENDO REALIZADO, VOCÊ PODE ENTRAR EM CONTATO COM O COMITÊ DE ÉTICA EM PESQUISA (CEP) DA UNIVERSIDADE DE SÃO PAULO PELO

ENDEREÇO: $\quad$ ESCOLA DE ARTES, CIENNCIAS E UNIVERSIDADE DE SÃO PAULO AV. ARLINDO BÉTTIO, 1000 ERMELINO MATARAZZO SÃO PAULO - SP CEP: 03828-000. INFORMAÇÕES: CEP EACH TELEFONE: 3091-1046 EMAIL: CEP-EACH@USP.BR ATENDIMENTO: SEGUNDA A SEXTA-FEIRA, DAS 10H ÀS 12H E DAS 14H ÀS 16H. LOCALIZAÇÃO: SALA T14 - I1.O COMITÊ DE ÉTICA É RESPONSÁVEL PELA AVALIAÇÃO E COMPANHAMENTO DOS ASPECTOS ÉTICOS DE TODAS AS PESQUISAS ENVOLVENDO SERES HUMANOS, VISANDO ASSEGURAR A PROTEÇÃO, A DIGNIDADE, OS DIREITOS, A SEGURANÇA E O BEM-ESTAR DO SUJEITO DA PESQUISA.

Finalmente, tendo eu compreendido perfeitamente tudo o que me foi informado sobre a participação do menor sobre minha responsabilidade na mencionada pesquisa e estando consciente dos meus direitos, das minhas responsabilidades, dos riscos e dos benefícios que a nossa participação implicam, concordo com a participação e para isso eu DOU O MEU CONSENTIMENTO SEM QUE PARA ISSO EU TENHA SIDO FORÇADO OU OBRIGADO. 


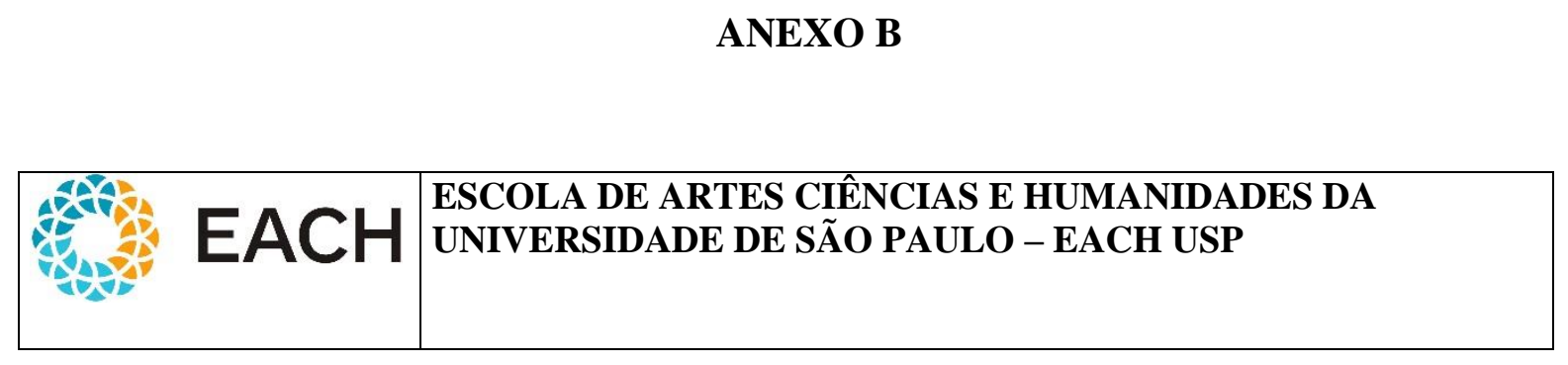

TERMO DE ASSENTIMENTO LIVRE E ESCLARECIDO

Título do Projeto: ANÁLISE DO DESEMPENHO DE TAREFA VIRTUAL EM PESSOAS COM
SÍNDROME DE DOWN

Você está sendo convidado (a) a participar de uma pesquisa que visa analisar a eficácia da utilização de realidade virtual na aprendizagem motora em pessoas com Síndrome de Down. Seus pais ou responsáveis já permitiram que você participe.

Os participantes dessa pesquisa têm idade acima de 8 anos. Você não precisa participar da pesquisa se não quiser, é um direito seu, não terá nenhum problema se desistir.

O jogo MoveHero apresenta esferas que caem, em quatro colunas imaginárias na tela do computador, no ritmo de uma música, a tarefa consiste em não deixar essas esferas caírem. O jogo capta os movimentos do participante por meio de uma webcam, a uma distância predeterminada da tela do computador. Portanto, o jogo exige que o participante tenha uma estratégia de antecipar o movimento para alcançar as esferas dentro desses círculos e transformam a pontuação alcançada em dados importantes para análises futuras.

A sua participação irá ajudar com informações que nos permitirão identificar se jogos com realidade virtual propiciam aprendizagem motora em pessoas com Síndrome Down e estes resultados podem ser importantes para oferecer aos profissionais de reabilitação maior conhecimento sobre a utilização da realidade virtual como recurso terapêutico e contribuir no processo de reabilitação deste público.

Ninguém saberá que você está participando da pesquisa, não falaremos a outras pessoas, nem daremos a estranhos as informações que você nos der. "Os resultados da pesquisa vão ser publicados, mas sem identificar os participantes da pesquisa”. Quando terminarmos a pesquisa poderemos deixar estes jogos para serem usados por qualquer pessoa que queira treinar suas habilidades ou melhorar sua capacidade de aprendizagem motora, e possa fazer isso de forma divertida. 
Se você tiver alguma dúvida, você pode me perguntar sou à pesquisadora Maely Pedrosa Pimentel. Eu escrevi os telefones na parte de baixo desse texto. Você irá preencher um questionário e jogar com o computador. Você será auxiliado pelo (a) pesquisador (a) e você não precisa ter nenhum conhecimento prévio do jogo que são divertidos e desafiadores. O jogo será realizado uma vez por semana por um período de 15 semanas seguidas, cada sessão pode demorar aproximadamente 30 minutos.

Você irá jogar em uma sala reservada com a presença apenas dos pesquisadores e profissionais qualificados para ajudar você. Se você sentir qualquer desconforto pode pedir para parar e será auxiliado pelos profissionais responsáveis.

Mestranda Maely Pedrosa Pimentel

Fone: (27) $99998-0280$

E-mail: maelypedrosa@usp.br

Endereço: Rua Arlindo Béttio, 1000

Ermelino Matarazzo/SP

CEP: 03828-000 


\section{DECLARACÃO DE ASSENTIMENTO DA CRIANCA DA PESQUISA:}

$\mathrm{Eu}$, , tendo sido convidado (a) a participar como voluntário (a) da pesquisa ANÁLISE DO DESEMPENHO DE TAREFA VIRTUAL EM PESSOAS COM SÍNDROME DE DOWN, entendi as coisas ruins e as coisas boas que podem acontecer. Entendi que posso dizer "sim" e participar, mas que, a qualquer momento, posso dizer "não" e desistir que ninguém vai ficar furioso. Os pesquisadores tiraram minhas dúvidas e conversaram com os meus responsáveis. Recebi uma cópia deste termo de assentimento e li e concordo em participar da pesquisa.

de 201

Assinatura da Criança participante

Endereço do Comitê de Ética em Pesquisa para recurso ou reclamações do sujeito pesquisado

Comitê de Ética em Pesquisa da Escola de Artes, Ciências e Humanidades Universidade de São Paulo. Av. Arlindo Béttio, 1000 Ermelino Matarazzo

São Paulo - SP CEP: 03828-000. Informações: INFORMAÇÕES: CEP EACH TELEFONE: 3091-1046 EMAIL: CEP-EACH@USP.BR ATENDIMENTO: SEGUNDA A SEXTAFEIRA, DAS 10H ÀS 12H E DAS 14H ÀS 16H. LOCALIZAÇÃO: SALA T14 - I1. Zack Magiezi

\begin{tabular}{|l|l|}
\hline $\begin{array}{l}\text { Assinatura ou impressão datiloscópicada } \\
\text { responsável legal e rubricar as demais páginas }\end{array}$ & $\begin{array}{l}\text { Responsável pela pesquisa: Maely Pedrosa } \\
\text { Pimentel (Rubricar as demais páginas) }\end{array}$ \\
\hline
\end{tabular}

IDENTIFICAÇÃO DO RESPONSÁVEL LEGAL

Nome completo:

Grau de parentesco com o participante:

Documento identificação: 
ANEXO C

CARACTERIZAÇÃO DA AMOSTRA

\section{PERFIL SOCIODEMOGRÁFICO}

1. Nome completo:

2. Sexo: ( ) Feminino ( ) Masculino

3. Escolaridade: ( ) Escola Especial ( ) Fundamental completo/incompleto

( ) Médio completo/incompleto ( ) Superior completo/incompleto

4. Estado Civil: ( ) Casado ( ) Divorciado ( ) solteiro ( ) Viúvo

5. Escreve:( ) Sim ( ) Não

6. Escreve o nome: ( ) Sim ( ) Não

7. Faz cópia:（） Sim （） Não

8. Leitura de palavras simples: ( ) Sim ( ) Não

9. Leitura de Frases: ( ) Sim （） Não

10. Identifica números: ( ) Sim （） Não

Fonte: Dados adaptados de Trigueiro et al, 2011

\section{PERFIL TECNOLÓGICO}

1. Experiência com computador: （） Sim （） Não

2. Há quanto tempo faz uso de computador:

3. Nível de experiência com computador: ( ) Bom ( ) Médio ( ) Regular ( ) Ruim ( ) Nenhum

4. Faz uso diário: ( ) Sim ( ) Não

5. Utiliza o computador quantas horas por dia:

6. Faz uso de Internet: ( ) facebook ( ) Jogos ( ) YouTube ( ) Outros 
1. Tempo de diagnóstico:

2. Utiliza Linguagem oral: ( ) Sim ( ) Não ( ) Às vezes

3. Escolhe Objetos/brinquedos de interesse:( ) Sim ( ) Não ( ) Às vezes

4. Mostra interesse por objetos apresentados: ( ) Sim ( ) Não ( ) Às vezes

5. Simbolismo: ( ) Sim ( ) Não ( ) Às vezes

6. Apresenta Estereotipia: ( ) Sim ( ) Não ( ) Às vezes

7. Apresenta ecolalia: ( ) Sim ( ) Não ( ) Às vezes

8. Inicia Interação: ( ) Sim ( ) Não ( ) Às vezes

9. Dialogo: ( ) Sim ( ) Não ( ) Às vezes

10. Apresenta boa função auditiva: ( ) Sim ( ) Não ( ) Às vezes

11. Apresenta boa função visual: ( ) Sim ( ) Não （） Faz uso de óculos

12. Fala inteligível: ( ) Sim ( ) Não ( ) Às vezes

13: Lado dominante em MMSS: ( ) Direito （）Esquerdo （） Usa as duas mãos

14. Tem algum problema motor: ( ) Sim ( ) Não Qual:

15. Marcha: ( ) Independente （）Com apoio （） Não Deambula

16. Apresenta deficiência cognitiva: ( ) Sim （） Não

17. Faz uso de medicamento controlado: ( ) Sim ( ) Não Qual:

Fonte: Dados adaptados de Trigueiro et al, 2011

Nome do responsável:

Pesquisador responsável:

Data: 
ANEXO D

Medida de Independência Funcional (MIF) (Riberto et al., 2004)

18 tarefas -1 a 7 pontos / 6 dimensões

MFI total

$(18-126)$

Subscore motor

$(1-91)$

Subescore cognitivo (1-35)

\begin{tabular}{|c|l|}
\hline \multicolumn{2}{|l}{ NIVEIS } \\
\hline 7 & Independência completa (em segurança , em tempo
\end{tabular}

\begin{tabular}{l|l}
6 & Independência modificada (ajuda técnica)
\end{tabular} Dependência modificada

\begin{tabular}{|c|c|c|c|}
\hline \multirow[t]{4}{*}{ Subescore cognitivo ___ $(1-35)$} & 3 & Ajuda moderada (individuo $\geq 50 \%$ ) & \multirow[t]{4}{*}{ AЛUDA } \\
\hline & \multicolumn{2}{|r|}{ Dependência completa } & \\
\hline & 2 & Ajuda máxima (individuo $\geq 25 \%$ ) & \\
\hline & 1 & Ajuda total (individuo $\geq 0 \%$ ) & \\
\hline AUTO CUIDADO & Nível & \multicolumn{2}{|l|}{ Comentários } \\
\hline \multicolumn{4}{|l|}{ A. Alimentação } \\
\hline \multicolumn{4}{|l|}{ B. Higiene pessoal } \\
\hline \multicolumn{4}{|l|}{ C. Banho (lavar corpo) } \\
\hline \multicolumn{4}{|l|}{ D. Vestir-se da cintura para cima } \\
\hline \multicolumn{4}{|l|}{ E. Vestir-se da cintura para baixo } \\
\hline \multicolumn{4}{|l|}{ F. Uso do vaso sanitário } \\
\hline \multicolumn{4}{|l|}{ CONTROLE DOS ESFÍNCTERES } \\
\hline \multicolumn{4}{|l|}{ G. Controle de urina } \\
\hline \multicolumn{4}{|l|}{ H. Controle de fezes } \\
\hline \multicolumn{4}{|c|}{ MOBILIDADE / TRANSFERENNCIAS } \\
\hline \multicolumn{4}{|c|}{ I. Leito, cadeira, cadeira de rodas } \\
\hline \multicolumn{4}{|l|}{ J. Sanitário } \\
\hline \multicolumn{4}{|l|}{ K. Banheira, chuveiro } \\
\hline \multicolumn{4}{|l|}{ LOCOMOCÃ̃O } \\
\hline \multirow{2}{*}{ L. Marcha, cadeira de rodas } & M & & \\
\hline & $\mathrm{C}$ & & \\
\hline \multicolumn{4}{|l|}{ M. Escadas } \\
\hline \multicolumn{4}{|l|}{ COMUNICACÃO } \\
\hline \multirow{2}{*}{ N. Compreensão } & a & & \\
\hline & $\mathrm{v}$ & & \\
\hline \multirow{2}{*}{ O. Expressão } & $\mathrm{v}$ & & \\
\hline & & & \\
\hline \multicolumn{4}{|l|}{ COGNICCÃO SOCIAL } \\
\hline \multicolumn{4}{|l|}{ P. Interação social } \\
\hline Q. Resolução de problemas & & & \\
\hline R. Memória & & & \\
\hline TOTAL & & & \\
\hline
\end{tabular}


ANEXO E

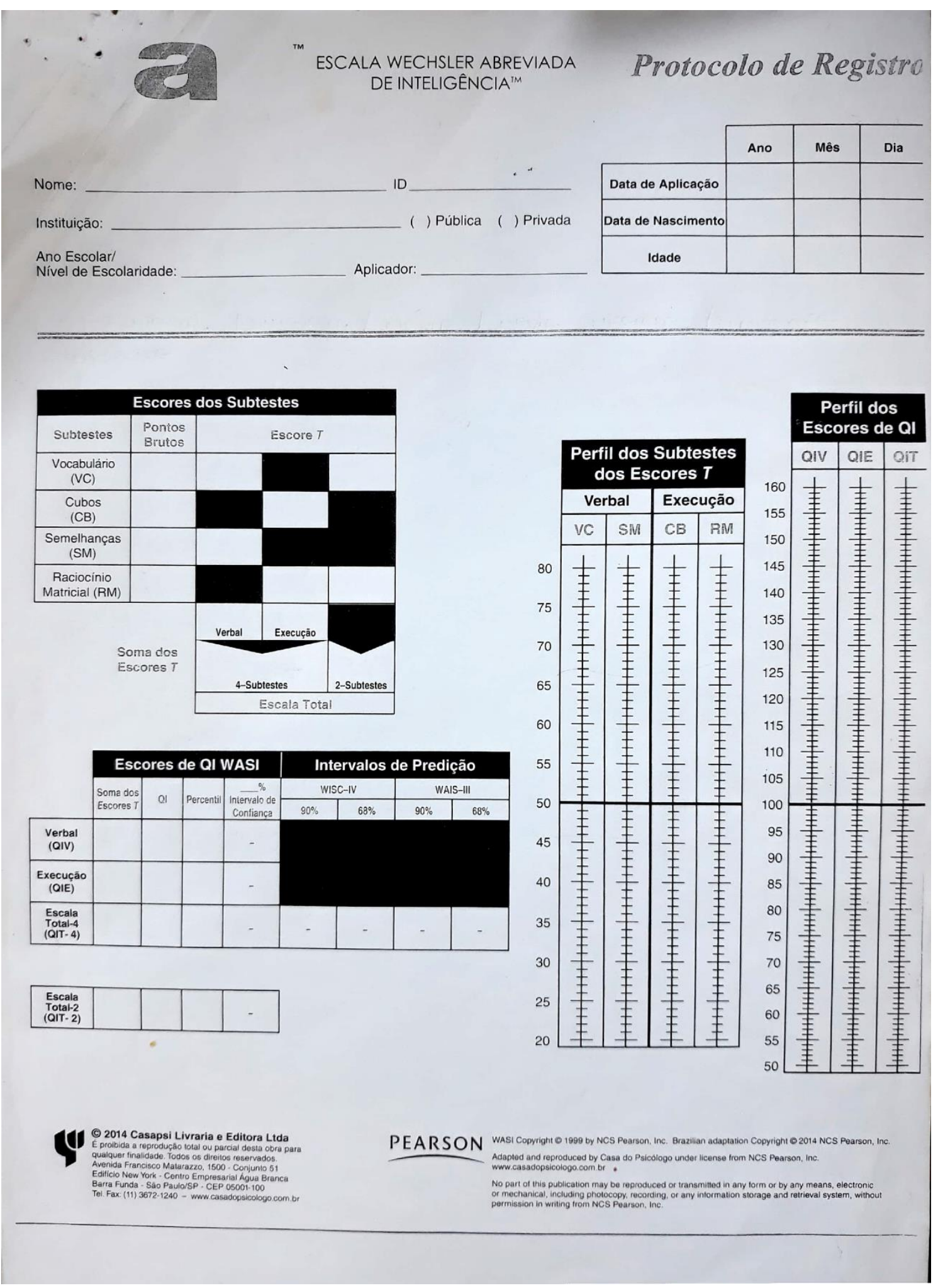




\section{Vocabulário}

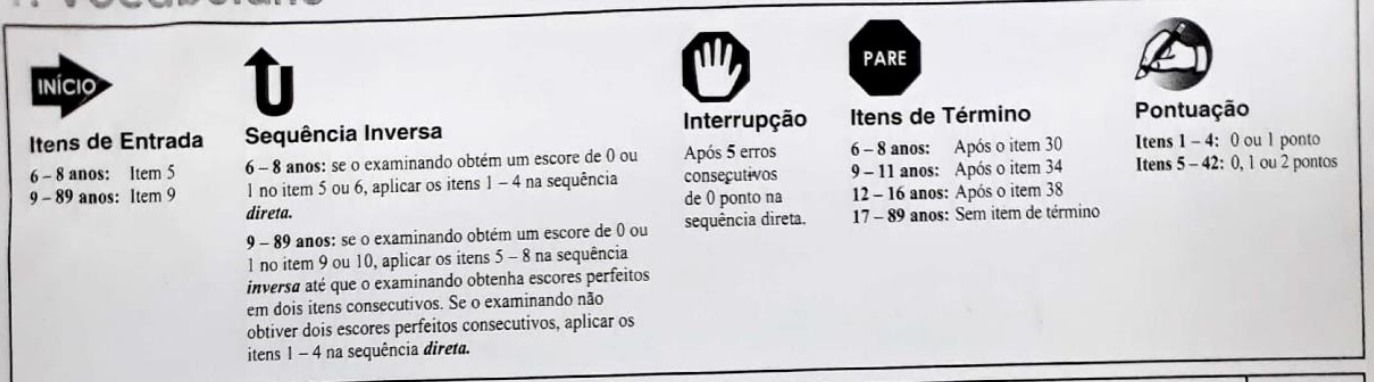

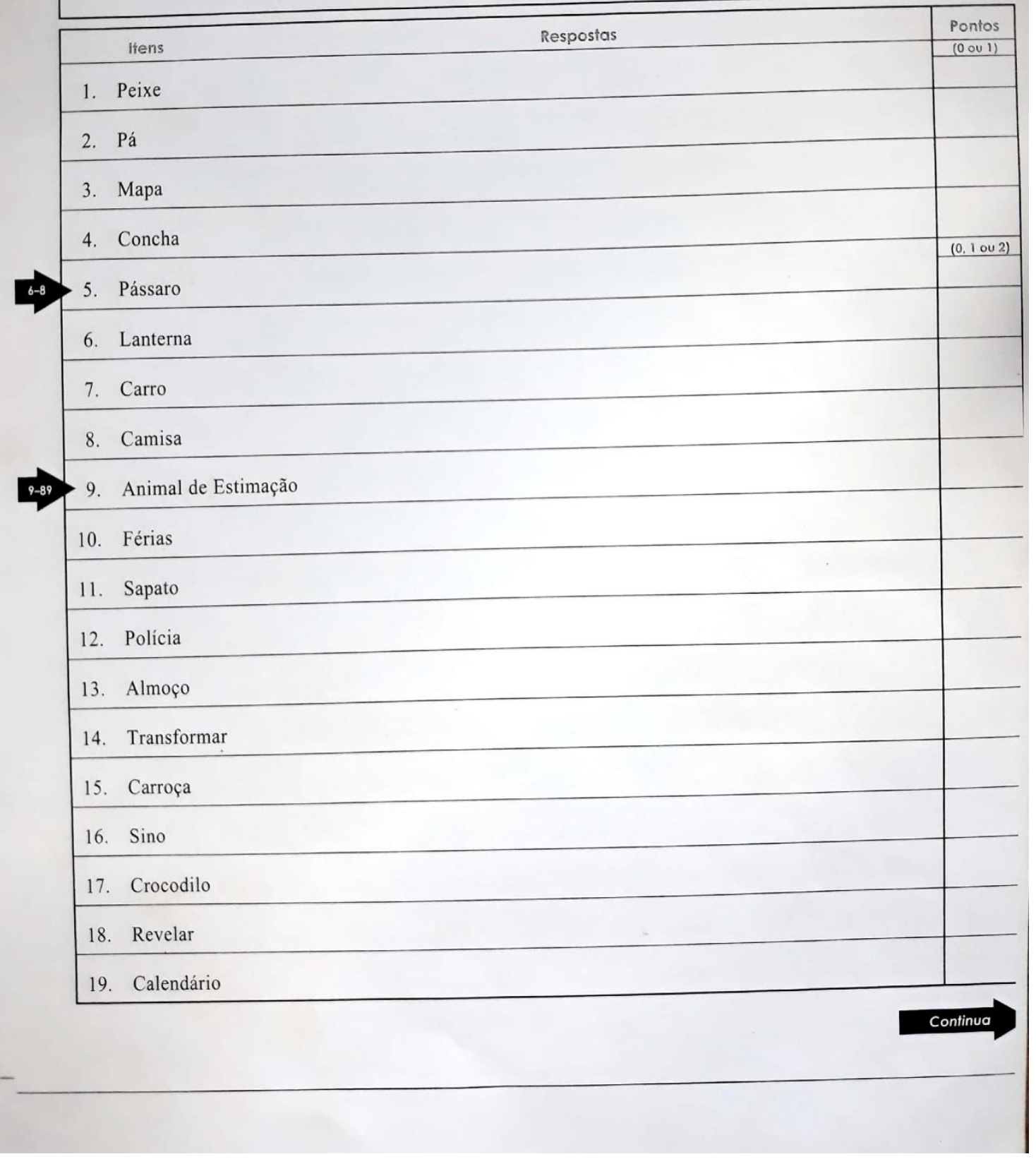


1. Vocabulário (Continuaçāo)

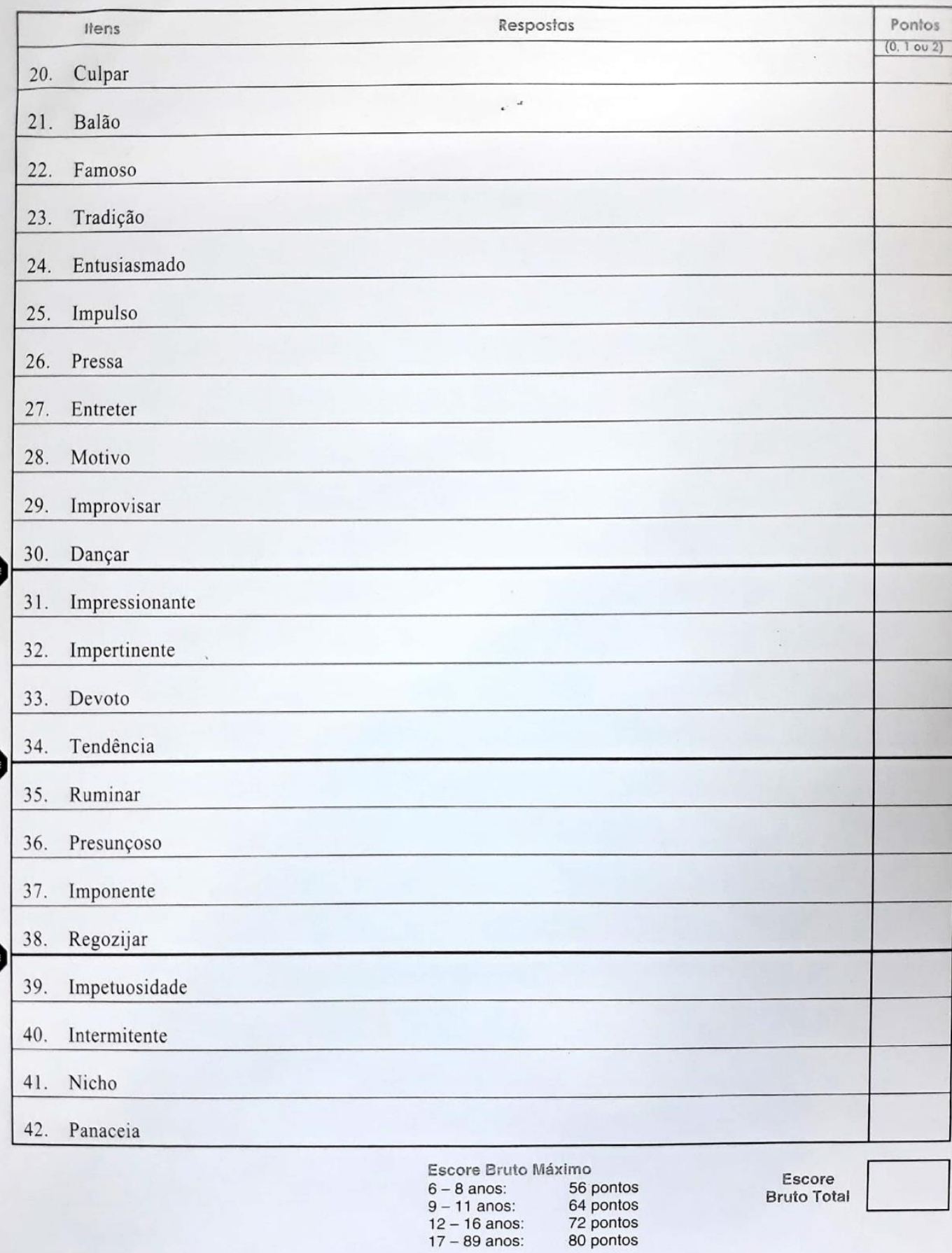




\section{Cubos}

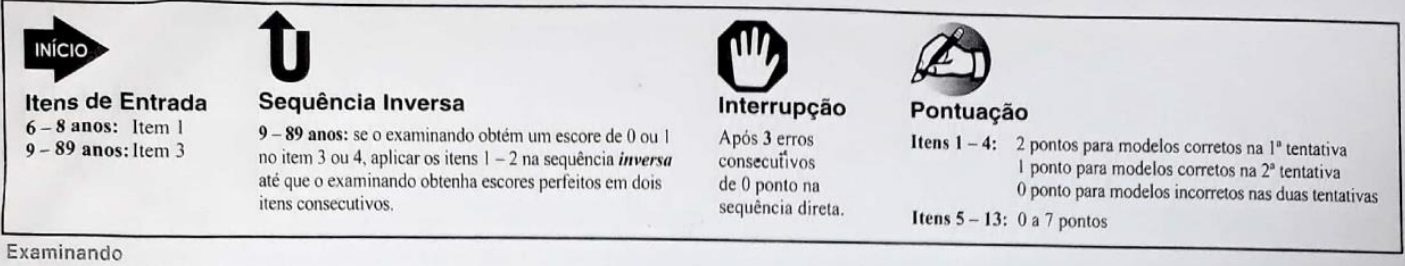

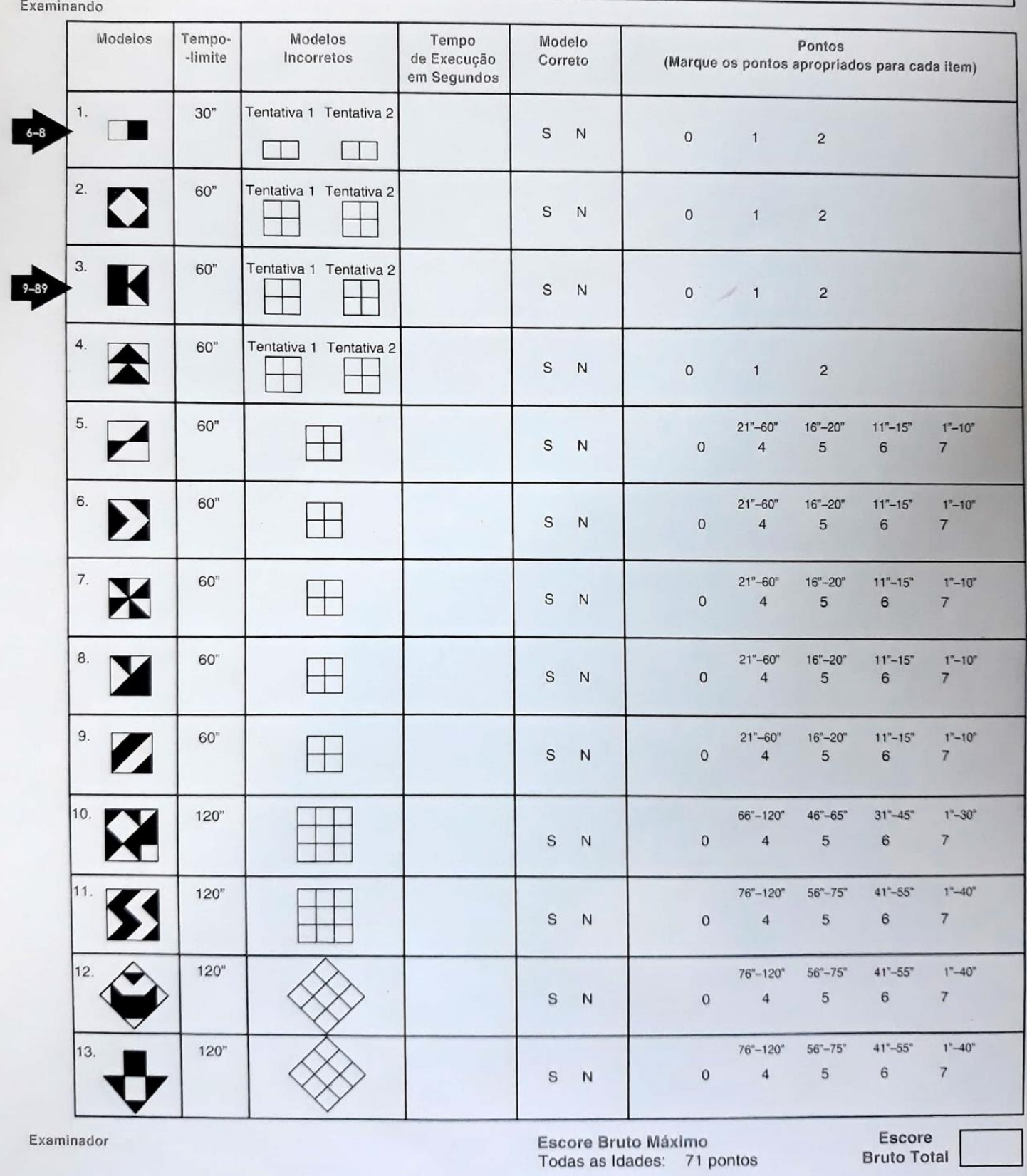


3. Semelhanças

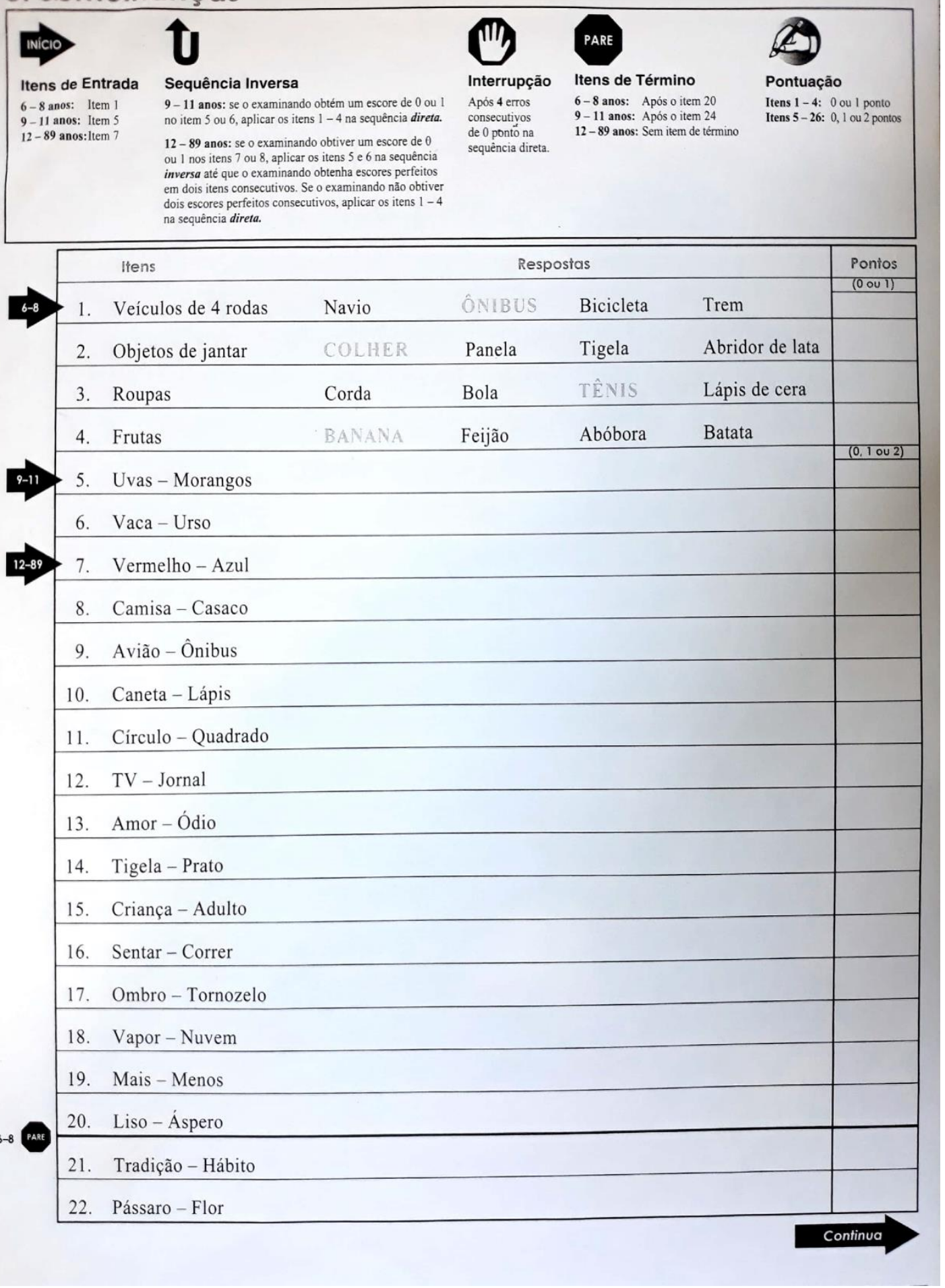


3. Semelhanças (Continuação)

\begin{tabular}{|ll|l|l|}
\hline \multicolumn{1}{|c|}{ Itens } & Resposias & Pontos \\
\cline { 2 - 4 }$(0.1$ ou 2)
\end{tabular}

\section{Raciocínio Matricial}

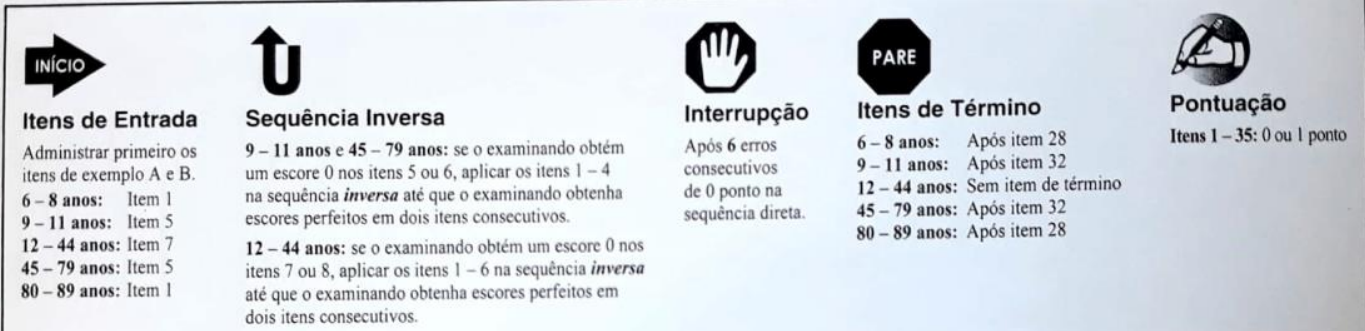

\begin{tabular}{|c|c|c|c|c|c|c|c|}
\hline \multirow{2}{*}{$\begin{array}{l}\text { tiens } \\
\mathrm{A} .\end{array}$} & \multicolumn{6}{|c|}{$\begin{array}{c}\text { Aliternativas } \\
\text { (Marque a resposia do examinando) }\end{array}$} & \multirow[t]{2}{*}{$\begin{array}{l}\text { Pontos } \\
\text { (0 ou } 1)\end{array}$} \\
\hline & 1 & 2 & 3 & 4 & 5 & NS & \\
\hline B. & 1 & 2 & 3 & 4 & 5 & NS & \\
\hline 1. & 1 & 2 & 3 & 4 & 5 & NS & \\
\hline 2. & 1 & 2 & 3 & 4 & 5 & NS & \\
\hline 3. & 1 & 2 & 3 & 4 & 5 & NS & \\
\hline 4. & 1 & 2 & 3 & 4 & 5 & NS & \\
\hline 5. & 1 & 2 & 3 & 4 & 5 & NS & \\
\hline 6. & I & 2 & 3 & 4 & 5 & NS & \\
\hline 7. & I & 2 & 3 & 4 & 5 & NS & \\
\hline 8. & 1 & 2 & 3 & 4 & 5 & NS & \\
\hline 9. & 1 & 2 & 3 & 4 & 5 & NS & \\
\hline 10. & 1 & 2 & 3 & 4 & 5 & NS & \\
\hline 11. & 1 & 2 & 3 & 4 & 5 & NS & \\
\hline 12. & 1 & 2 & 3 & 4 & 5 & NS & \\
\hline 13. & 1 & 2 & 3 & 4 & 5 & NS & \\
\hline 14. & 1 & 2 & 3 & 4 & 5 & NS & \\
\hline 15. & 1 & 2 & 3 & 4 & 5 & NS & \\
\hline 16. & 1 & 2 & 3 & 4 & 5 & NS & \\
\hline 17. & 1 & 2 & 3 & 4 & 5 & NS & \\
\hline
\end{tabular}

\begin{tabular}{|c|c|c|c|c|c|c|c|c|}
\hline & \multirow{2}{*}{$\begin{array}{c}\text { Hens } \\
18 .\end{array}$} & \multicolumn{6}{|c|}{$\begin{array}{l}\text { Alternativas } \\
\text { (Marque a resposta do examinando) }\end{array}$} & \multirow[t]{2}{*}{$\begin{array}{l}\text { Pontos } \\
\left(\begin{array}{l}0 \\
\text { ou }\end{array} 1\right)\end{array}$} \\
\hline & & 1 & 2 & 3 & 4 & 5 & NS & \\
\hline & 19. & 1 & 2 & 3 & 4 & 5 & NS & \\
\hline & 20. & 1 & 2 & 3 & 4 & 5 & NS & \\
\hline & 21. & 1 & 2 & 3 & 4 & 5 & NS & \\
\hline & 22. & 1 & 2 & 3 & 4 & 5 & NS & \\
\hline & 23. & 1 & 2 & 3 & 4 & 5 & NS & \\
\hline & 24. & 1 & 2 & 3 & 4 & 5 & NS & \\
\hline & 25. & 1 & 2 & 3 & 4 & 5 & NS & \\
\hline & 26. & 1 & 2 & 3 & 4 & 5 & NS & \\
\hline & 27. & 1 & 2 & 3 & 4 & 5 & NS & \\
\hline \multirow{4}{*}{$\begin{array}{l}6-8 \\
80-89\end{array}$} & 28. & 1 & 2 & 3 & 4 & 5 & NS & \\
\hline & 29. & 1 & 2 & 3 & 4 & 5 & $\mathrm{NS}$ & \\
\hline & 30. & 1 & 2 & 3 & 4 & 5 & NS & \\
\hline & 31. & 1 & 2 & 3 & 4 & 5 & NS & \\
\hline \multirow{5}{*}{ 9-11 PARE } & 32. & 1 & 2 & 3 & 4 & 5 & NS & \\
\hline & 33. & 1 & 2 & 3 & 4 & 5 & NS & \\
\hline & 34. & 1 & 2 & 3 & 4 & 5 & NS & \\
\hline & 35. & 1 & 2 & 3 & 4 & 5 & NS & \\
\hline & $\begin{array}{l}\text { Escore } \\
6-8 \text { and } \\
9-11 \text { ar } \\
12-44 \\
45-79 \\
80-89\end{array}$ & $\begin{array}{l}\text { ruto } \\
\text { s: } \\
\text { os: } \\
\text { nos: } \\
\text { nos: } \\
\text { nos: }\end{array}$ & $\begin{array}{l}\text { Máxin } \\
28 \text { por } \\
32 \text { por } \\
35 \text { por } \\
32 \text { por } \\
28 \text { por }\end{array}$ & & & $\begin{array}{c}\text { core } \\
\text { Tot }\end{array}$ & & \\
\hline
\end{tabular}


3. Semelhanças (Continuação)

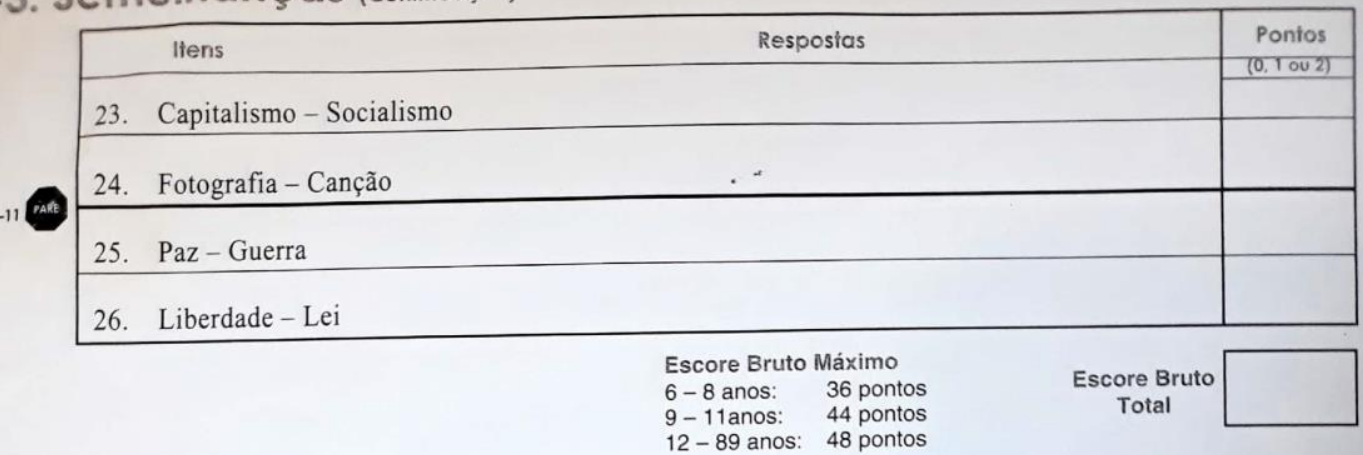

\section{Raciocínio Matricial}

\begin{tabular}{|c|c|c|c|c|}
\hline Itens de Entrada & Sequência Inversa & Interrupção & Itens de Término & Pontuação \\
\hline $\begin{array}{l}\text { Administrar primeiro os } \\
\text { itens de exemplo A e B. } \\
\text { 6-8 anos: Item I } \\
9-11 \text { anos: Item } 5 \\
12-44 \text { anos: Item } 7 \\
45-79 \text { anos: Item } 5 \\
80-89 \text { anos: Item I }\end{array}$ & $\begin{array}{l}9 \text { - } 11 \text { anos e } 45-79 \text { anos: se o examinando obtém } \\
\text { um escore } 0 \text { nos itens } 5 \text { ou } 6 \text {, aplicar os itens } 1-4 \\
\text { na sequência inversa até que o examinando obtenha } \\
\text { escores perfeitos em dois itens consecutivos. } \\
12-44 \text { anos: se o examinando obtém um escore } 0 \text { nos } \\
\text { itens } 7 \text { ou } 8 \text {, aplicar os itens } 1-6 \text { na sequência inversa } \\
\text { até que o examinando obtenha escores perfeitos em } \\
\text { dois itens consecutivos. }\end{array}$ & $\begin{array}{l}\text { Após } 6 \text { erros } \\
\text { consecutivos } \\
\text { de } 0 \text { ponto na } \\
\text { sequência direta. }\end{array}$ & $\begin{array}{l}\text { 6-8 anos: Após item } 28 \\
9-11 \text { anos: Após item } 32 \\
12-44 \text { anos: Sem item de término } \\
45-79 \text { anos: Após item } 32 \\
80-89 \text { anos: Após item } 28\end{array}$ & Itens 1 - 35 : 0 ou 1 ponto \\
\hline
\end{tabular}

\begin{tabular}{|c|c|c|c|c|c|c|c|}
\hline Hens & \multicolumn{6}{|c|}{$\begin{array}{c}\text { Aliernativas } \\
\text { (Marque a resposia do examinando) }\end{array}$} & $\begin{array}{l}\text { Pontos } \\
(0 \text { ou } 11)\end{array}$ \\
\hline A. & 1 & 2 & 3 & 4 & 5 & NS & \\
\hline B. & 1 & 2 & 3 & 4 & 5 & NS & \\
\hline 1. & 1 & 2 & 3 & 4 & 5 & NS & \\
\hline 2. & 1 & 2 & 3 & 4 & 5 & NS & \\
\hline 3. & 1 & 2 & 3 & 4 & 5 & NS & \\
\hline 4. & 1 & 2 & 3 & 4 & 5 & NS & \\
\hline 5. & 1 & 2 & 3 & 4 & 5 & NS & \\
\hline 6. & I & 2 & 3 & 4 & 5 & NS & \\
\hline 7. & I & 2 & 3 & 4 & 5 & NS & \\
\hline 8. & 1 & 2 & 3 & 4 & 5 & NS & \\
\hline 9. & 1 & 2 & 3 & 4 & 5 & NS & \\
\hline 10. & 1 & 2 & 3 & 4 & 5 & NS & \\
\hline 11. & 1 & 2 & 3 & 4 & 5 & NS & \\
\hline 12. & 1 & 2 & 3 & 4 & 5 & NS & \\
\hline 13. & 1 & 2 & 3 & 4 & 5 & NS & \\
\hline 14. & 1 & 2 & 3 & 4 & 5 & NS & \\
\hline 15. & 1 & 2 & 3 & 4 & 5 & NS & \\
\hline 16. & 1 & 2 & 3 & 4 & 5 & NS & \\
\hline 17. & 1 & 2 & 3 & 4 & 5 & NS & \\
\hline
\end{tabular}

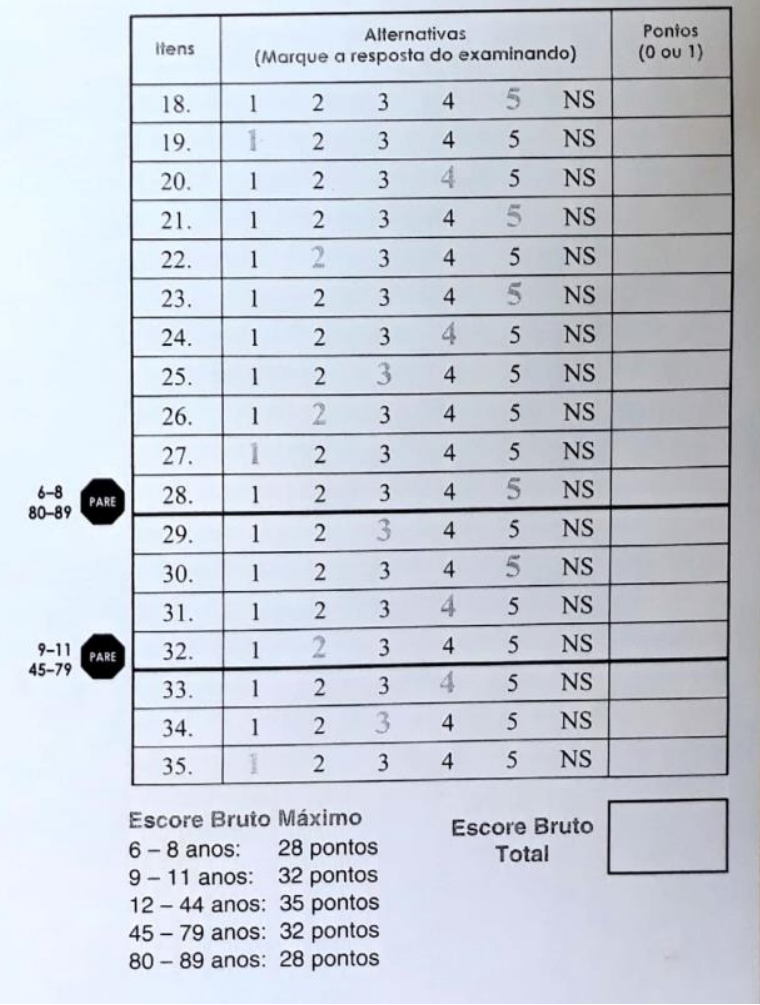


Atitude em relação à testagem (ex: rapport, interesse, hábitos de trabalho, motivação, comunicação, reação frente ao sucesso/fracasso):

Aparência física:

Atenção:

Problema visual/auditivo/motor:

Linguagem (idioma dominante, idioma falado em casa, linguagem expressiva/receptiva)

Afeto/humor:

Comportamentos não usuais/verbalizações:

Outras observações: 